\title{
Full-scale CFD simulation of tsunamis. Part 2: Boundary layers and bed shear stresses
}

\author{
Larsen, Bjarke Eltard; Fuhrman, David R.
}

Published in:

Coastal Engineering

Link to article, DOI:

10.1016/j.coastaleng.2019.04.011

Publication date:

2019

Document Version

Peer reviewed version

Link back to DTU Orbit

Citation (APA):

Larsen, B. E., \& Fuhrman, D. R. (2019). Full-scale CFD simulation of tsunamis. Part 2: Boundary layers and bed shear stresses. Coastal Engineering, 151, 42-57. https://doi.org/10.1016/j.coastaleng.2019.04.011

\section{General rights}

Copyright and moral rights for the publications made accessible in the public portal are retained by the authors and/or other copyright owners and it is a condition of accessing publications that users recognise and abide by the legal requirements associated with these rights.

- Users may download and print one copy of any publication from the public portal for the purpose of private study or research.

- You may not further distribute the material or use it for any profit-making activity or commercial gain

- You may freely distribute the URL identifying the publication in the public portal

If you believe that this document breaches copyright please contact us providing details, and we will remove access to the work immediately and investigate your claim 


\title{
Full-scale CFD simulation of tsunamis. Part 2: Boundary layers and bed shear stresses
}

\author{
Bjarke Eltard Larsen ${ }^{\mathrm{a}, *}$, David R. Fuhrman ${ }^{\mathrm{a}}$ \\ ${ }^{a}$ Technical University of Denmark, Department of Mechanical Engineering, Section of \\ Fluid Mechanics, Coastal and Maritime Engineering, DK-2800 Kgs. Lyngby, Denmark
}

\begin{abstract}
This paper presents results from numerical simulations of the propagation and run-up of full scale tsunamis, using a Reynolds-Averaged NavierStokes model, with emphasis on the resulting boundary layers and bed shear stresses. Spatial distributions of the Shields and Rouse parameters during run-up and draw-down show that for the tsunamis considered, with a sediment grain size corresponding to medium sand, considerable sediment transport (Shields parameter $\mathrm{O}(10)-\mathrm{O}(100)$ ) can be expected during run-up and that the sediment transport can be expected to be dominated by suspended load. The results likewise show that the expected sediment transport during draw-down will similarly be considerable and dominated by suspension. The tsunami-induced boundary layers are monitored in time, and the observed boundary layer thickness ranges from spanning only a small fraction of the water depth to spanning the entire depth. The velocity profiles beneath the tsunamis are shown to have good correspondence with a logarithmic profile within the boundary layer. Similarly, the bed shear stresses beneath the tsunamis are investigated and a new and simple engineering model is developed for predicting the temporal variation of the bed shear stress based only on a free-stream velocity signal. The new engineering model is shown give better predictions for the bed shear stress than a standard Manning approach, and is likewise shown (in the Appendix) to produce reasonable predictions for shorter (wind scale) waves. It is finally also shown how the temporal evolution of the boundary layer thickness can be predicted based on the free-stream velocity signal alone. The results presented here are Part 2 of a larger study, where Part 1 presents the model validation and detailed descriptions of the run-up process.
\end{abstract}

\footnotetext{
* Corresponding author

Email address: bjelt@mek.dtu.dk (Bjarke Eltard Larsen)
} 
Keywords: Tsunamis, Computational Fluid Dynamics, Boundary layers, Shear stress, Turbulence modelling

\section{Introduction}

The potentially fatal impact of large tsunamis is well known. The two recent major tsunami events, the Boxing Day tsunami in 2004 in the Indian Ocean, and the Tohoku tsunami near Japan in 2011 were responsible for approximately 230,000 and 20,000 fatalities, respectively (Suppasri et al., 2012). Therefore, it is natural that most tsunami research in the past has rightly focused on predicting run-up height and inundation distance, as increased knowledge in these areas can potentially save human lives.

In addition to fatalities, tsunamis can also potentially have a long term effect on entire coastal regions. Beaches can get eroded, scour can occur around coastal structures, large sediment deposits can enter harbours, and sediment deposited inland can hinder recovery work. Following the Tohoku tsunami, it was reported that $90 \%$ of the beach had disappeared in the Takata Matsubara area (Japan), and it was estimated that the total volume of morphological change over an approximately $2000 \mathrm{~m}$ stretch was $1.9 \mathrm{x}$ $10^{6} \mathrm{~m}^{3}$ (Kato et al., 2012; Yamashita et al., 2016). Before-and-after satellite images of the beaches of Banda Aceh, Indonesia from the 2004 Indian Ocean tsunami likewise show large scale erosion, with the coast locally retreating up to $200 \mathrm{~m}$ (Paris et al., 2009; Borrero et al., 2006). For other field studies of the morphological impacts of tsunamis see e.g. Udo et al. (2016) and Kuriyama et al. (2014). The above-mentioned field studies all provide some useful insight on tsunami induced sediment transport and morphology. They do not, however, give insight into the detailed transport patterns that emerge, which is needed if prediction of tsunami-induced sediment transport should be improved.

Despite the potentially large effect on beaches and coastal profiles the tsunami-induced sediment transport and morphology has, apart from the previous mentioned surveys, received relatively little attention compared to e.g. run-up height and inundation distance. The few studies that have treated this have primarily been numerical using the non-linear shallow water (NLSW) equation models. These have either been two-dimensional horizontal $(2 \mathrm{DH})$ where the flow is assumed uniform across the depth (e.g. Li et al. (2012), Kuriyama et al. (2014), Ontowirjo et al. (2013), Sugawara et al. $(2014 b))$ or three-dimensional where the vertical direction is resolved using a number of $\sigma$-layers. Often these have been reduced to two-dimensional 
vertical models (2DV) (e.g Apotsos et al., 2011a,b,c). For a more detailed review on numerical modelling of tsunami induced sediment transport using NLSW models see Sugawara et al. (2014a). Such models are reasonably good at handling tsunami propagation and inundation. They do not describe dispersion, however, and will therefore not be able to capture the splitting of steep tsunami wave fronts into an undular bore, nor do they describe wave breaking accurately. Furthermore, in 2DH models the flow is uniform across the depth, and hence the bed shear stress and resulting sediment transport is typically based on either a Manning coefficient, a Colebrook-White type friction formula or an assumed logarithmic velocity profile. Due to the very limited number of studies on tsunami-induced boundary layers it is not known how well these approximations work in such instances, however.

Studies relating to tsunami-induced boundary layers are seemingly limited to the field measurement of Lacy et al. (2012), as well as the numerical studies of Williams and Fuhrman (2016) and Tanaka et al. (2016). Lacy et al. (2012) showed that the tsunami-induced boundary layer from the 2010 Chilean Tsunami, measured off the coast of California, were expectedly larger than typical wind wave boundary layers, though still only spanning a small portion of the entire depth. In a one dimensional vertical (1DV) Reynolds-Averaged Navier-Stokes (RANS) model Williams and Fuhrman (2016) simulated a series of tsunami-scale boundary layers, emphasizing that they are both current-like due to their long duration, but also wave-like, in the sense that they are unsteady and that the boundary layer may not span the entire water depth, similar to observations made by Lacy et al. (2012). Williams and Fuhrman (2016) likewise proposed formulas for predicting tsunami boundary layer thickness and friction factors for various tsunami signals and various bed roughnesses. Their study was limited to offshore regions (depths $\geq 10 \mathrm{~m}$ ) to prevent the boundary layer being depth-limited, and the driving tsunami signal was treated as a time varying current. Treating the tsunami induced boundary layer as a time varying current has also been utilized in studies of tsunami induced scour around monopiles by Larsen et al. (2017) and Larsen et al. (2018). In an attempt to combat the uncertainties of the NLSW models regarding the bed-shear stress Tanaka et al. (2016) simulated tsunami run-up with a NLSW model coupled with a RANS model, using a $k-\omega$ turbulence model for describing the boundary layer. They showed that this gave different shear stress approximations compared to those that would be predicted using a Manning coefficient. It is unclear, however, exactly how they coupled the two models.

Despite this, it is an interesting attempt to remedy some of the uncertainties regarding the bed shear stresses predicted by NLSW models. 
Finally, tsunami-induced sediment transport has also been considered in a branch of the paleo-tsunami research community trying to predict flow characteristics of historic tsunamis based on sediment deposits, using what is normally referred to as inverse models. Many different inverse models exist see e.g. Moore et al. (2007), Soulsby et al. (2007) and Jaffe and Gelfenbuam (2007). These models all rely on numerous assumptions, and amongst the most common are: (1) sediments travel in suspension and (2) are not resuspended during draw-down. In an attempt to contribute to the paleo tsunami research, Johnson et al. (2016) studied deposits left by a breaking bore and concluded that an existing advection-settling model was able to predict flow depths within a factor two and velocities within a factor 1.5, thus showing a reasonable performance of one of the paleo tsunami inverse models. Yoshii et al. $(2017,2018)$ studied experimentally tsunami deposits in their $205 \mathrm{~m}$ long flume for a range of topographies. They concluded that the majority of the deposits came from the onshore flow. The return flow created seaward fining (sediment tending to have smaller grain sizes), something contrary to many paleo tsunami inverse models, a point also made by Paris et al. (2012). For a more complete overview of inverse models see Sugawara et al. (2014a), and a review on tsunami-seabed interaction in general can be found in Larsen (2018).

With the use of computational fluid dynamics (CFD) the present work aims at both qualitatively and quantitatively describing tsunami-induced boundary layers and shear stresses as well as the implications for sediment transport. The knowledge on boundary layers and bed shear stresses can be useful for implementation in "simpler" potential flow models (i.e. NLSW type or Boussinesq type), possibly improving their sediment transport predictive capabilities. The results can likewise be useful for the previously described inverse models, as it will shed light on the validity (or lack thereof) of some of the common assumptions made in these models.

The results presented in this work build on the same simulations presented in Larsen and Fuhrman (2018a) (hereafter referred to as Part 1). In Part 1 the numerical model was described, validated (for free surface elevations, run-up, wave breaking and bed shear stresses) and used to investigate in detail the run-up processes of full-scale tsunamis.

The remainder of the paper is organized as follows: In Section 2 the model is briefly described and the set-up of the model is provided. In Section 3 the model results for (1) Shields and Rouse parameters and (2) boundary layer dynamics are presented, and a new method for predicting instantaneous tsunami-induced boundary layer thickness and bed shear stress is proposed. In Section 4 overall conclusions are drawn. In Appendix A the 
performance of the proposed method is demonstrated for short waves.

\section{Model description and setup}

For a complete description of the CFD model employed in the present work the reader is referred to Part 1 . For the sake of efficiency, only an abbreviated description is provided here. The CFD simulations are performed in the two-phase volume of fluid method (VOF) flow model waves2FOAM developed by Jacobsen et al. (2012). Here, the Reynolds-averaged NavierStokes (RANS) equations are solved. To close the system the $k$ - $\omega$ model of Larsen and Fuhrman (2018b) is used, who extended the Wilcox (2006) model such that it is formally stable (i.e. does not un-physically produce turbulence) in the potential flow region beneath surface waves. For the turbulence quantities at the bottom the generalized wall function approach presented in Fuhrman et al. (2014) is used. These wall functions have also been used by e.g. Baykal et al. (2015), Larsen et al. (2016), Bayraktar et al. (2016) and Larsen and Fuhrman (2018b).

The tsunami waves in this study, will be specified as initial conditions and are the same as considered in Part 1. As an inspiration for the tsunamis the well-known Mercator yacht signal, taken during the Indian Ocean tsunami in 2004 was used. The leading wave of this signal was estimated by Madsen and Fuhrman (2008) to be approximately sinusoidal to have a wave height of $5 \mathrm{~m}$ and a period of $\mathrm{T}=13 \mathrm{~min}$ at a water depth of $h=14 \mathrm{~m}$. Specifically the tsunamis will be represented by a general $\mathrm{N}$-wave form (the summation of a positive and negative single wave) inspired by Madsen and Schäffer (2010), but with $x$-variation now included. The free-surface is given by

$$
\begin{aligned}
\eta(x, t) & =A_{1} \operatorname{sech}\left[\Omega_{1}\left(\left(t-t_{1}\right)-\frac{x-x_{0}}{\sqrt{g h}}\right)\right]^{2} \\
& -A_{2} \operatorname{sech}\left[\Omega_{2}\left(\left(t-t_{2}\right)-\frac{x-x_{0}}{\sqrt{g h}}\right)\right]^{2}
\end{aligned}
$$

where $A_{1}$ and $A_{2}$ are the amplitudes of the two single waves and $g$ is the gravitational acceleration. The effective frequencies $\Omega_{1}$ and $\Omega_{2}$ defines the time span of the two single waves according to $\Omega_{i}=2 \pi / T_{i}$ where $T_{i}$ can be interpreted as the effective period of the corresponding single wave, defined as the time where the surface elevations drops below $0.7 \%$ of the amplitude. In the above $x_{0}$ defines the center of the wave and $t_{1}$ and $t_{2}$ can be used to phase shift the two single waves. This signal can be reduced to a "single wave" by setting $A_{2}=0$. The initial horizontal velocity is then given by linear 


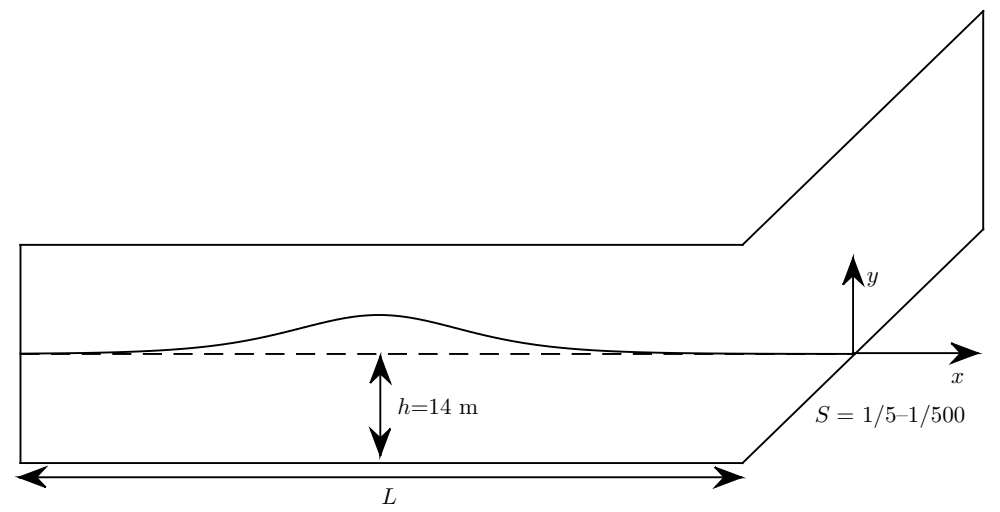

Figure 1: Layout of the computational domain, with origo positioned at the original shoreline. This sketch is a repeat from Part 1.

shallow water theory

$$
u(x, t)=\sqrt{\frac{g}{h}} \eta(x, t) .
$$

The vertical velocity is derived from the local continuity equation, and the pressure is calculated as hydrostatic.

In the simulations we consider the simple canonical case of $2 \mathrm{D}$ tsunami waves propagating over an initial constant depth region, before running up a constant slope. The waves will be initialized on a flat bed, which is one wave length long, such that the flat part of the domain houses the entire wave. The waves will then propagate and deform before reaching a constant slope region, where the slope will be systematically varied. A general setup of the computational domain can be seen in Figure 1.

Table 1 gives a summary of the cases to be considered in detail in this study, corresponding to a sub-set of those in Part 1. In the first two rows of the table $A_{2}=0$ and therefore these waves are single waves, with only a positive displacement. The third row contains an N-wave with a leading depression. The periods and phase shifts of the $\mathrm{N}$-wave are chosen to yield the same wave length and crest-to-trough wave height as the single wave cases. In Part 1 a total of 14 cases were presented, but here we only go into great detail with three of these, for the sake of brevity. These three are specifically chosen to represent different run-up scenarios as detailed in Part 1. The grain size of the bed is taken as $d=0.4 \mathrm{~mm}$ (medium sand) such that the roughness for the present cases is given by $k_{s}=2.5 d=0.001 \mathrm{~m}$. For all cases the domain is discretized into cells $\Delta y=0.25 \mathrm{~m}$ and $\Delta x=0.5 \mathrm{~m}$ and 


\begin{tabular}{ccccccccc}
\hline Case & $\mathrm{S}$ & $A_{1}[\mathrm{~m}]$ & $A_{2}[\mathrm{~m}]$ & $T_{1}[\mathrm{~s}]$ & $T_{2}[\mathrm{~s}]$ & $t_{1}[\mathrm{~s}]$ & $t_{2}[\mathrm{~s}]$ & $x_{0}[\mathrm{~m}]$ \\
\hline $\mathrm{S} 030$ & $1 / 30$ & 5 & 0 & 780 & 0 & 0 & 0 & -4990.5 \\
$\mathrm{~S} 200$ & $1 / 200$ & 5 & 0 & 780 & 0 & 0 & 0 & -7370.5 \\
\hline $\mathrm{N} 100$ & $1 / 100$ & 2.52 & 2.52 & 520 & 520 & 130 & -130 & -5970.5 \\
\hline
\end{tabular}

Table 1: Cases, slopes and initial wave parameters for the simulated cases considered in the present work.

from $5 \mathrm{~m}$ above the bed and lower the grid is gradually refined (using 51 cell) in the vertical with near-bed cells having $\Delta y=0.0014 \mathrm{~m}$ corresponding to $\Delta y / k_{s}=1.4$. The bottom $0.5 \mathrm{~m}$ is discretized into 21 cells.

\section{Model results}

In this section the modelled results will be presented. The first part of this section will focus on the spatial distribution of the Shields and Rouse parameters during run-up and draw-down of the three characteristic tsunami events in Table 1. The next part will focus on the tsunami-induced boundary layers, describing both the temporal development in boundary layer thickness and the shape of the velocity profiles. Finally, based on the results from the detailed boundary layer analysis a new engineering approach for estimating the friction velocity (and hence the bed shear stress) will be developed.

In this section some mentioning of the run-up characteristics of the tsunami will be made, but for a full discussion on these, please see Part 1 .

\subsection{Shields and Rouse parameters}

In the present study to save computational time, only the hydrodynamics were solved for (i.e. velocities, surface elevations, turbulence and bed shear stresses). However, some conclusions regarding sediment transport can be made by looking at the Shields and Rouse parameters. The Shields parameter is a non-dimensional number proportional to the ratio of driving and stabilizing forces on sediment grains and is defined (Fredsøe and Deigaard, 1992) as

$$
\theta=\frac{U_{f}\left|U_{f}\right|}{g(s-1) d}
$$

where $s=2.65$ is the assumed relative sediment density and $U_{f}$ is the friction velocity. The Rouse parameter can be interpreted as proportional 
to the ratio between settling velocity and near-bed turbulent fluctuations, and is conventionally defined (Fredsøe and Deigaard, 1992)

$$
Z=\frac{w_{s}}{\kappa\left|U_{f}\right|}
$$

where $\kappa=0.4$ is the von Kármán's constant and $w_{s}$ is the fall velocity. On this basis, analogous to (3), we define

$$
Z^{-2}=\frac{\kappa^{2} U_{f}\left|U_{f}\right|}{w_{s}^{2}}=\frac{\kappa^{2} g(s-1) d}{w_{s}^{2}} \theta
$$

such that (for a given grain size $d$ and relative density, $s$ ) $\theta$ and $Z^{-2}$ differ by only a constant and can thus be represented with a single plot. Throughout the present work $w_{s}=0.0527 \mathrm{~m} / \mathrm{s}$ is taken as the settling velocity (calculated as described in Fredsøe and Deigaard, 1992). According to Fredsøe and Deigaard (1992) and Sumer and Fredsøe (2002) $Z<2-2.5\left(\left|Z^{-2}\right|>0.18-\right.$ $0.25)$ is typically necessary for sediment to go into suspension, and sediment will be distributed more uniformly across the boundary layer as $Z$ is lowered (or $\left|Z^{-2}\right|$ increased).

It is important to stress that the result for $\theta$ and $Z^{-2}$ presented herein, are based on the single grain size considered, again corresponding to medium sand. Other grain sizes would naturally result in different values for $\theta$ and $Z^{-2}$, and as a result conclusions regarding sediment transport must be interpreted in this context. This will be further elaborated in the end of this section.

As a first case we will consider case S200 (a single wave running up a slope of $S=1 / 200$ ), which runs up as a breaking bore. Figure 2 shows $\theta$ and $Z^{-2}$ as a function of both space and time, and to complement the analysis Figure 3 shows surface elevations and velocities at three different instants, which are marked by the horizontal dashed lines in Figure 2. The times correspond to the tsunami shoaling (Figure 3a), inundating (Figure 3b) and receding (Figure 3c). During shoaling it can be seen that the steep tsunami wave front has split, and that a short wave is riding on the front (Figure 3a). The short wave was not able to maintain its shape, however, and it broke before reaching the shore (this was shown in Part 1 to be typical of tsunamis running up as breaking bores). For more details regarding the characteristics of tsunamis running up as breaking bores please see Part 1. The very steep tsunami wave front in Figure 3a can be seen to give a very sudden increase in the velocity. This increase in velocity, of course, causes $\theta$ and $Z^{-2}$ to increase, as shown in Figure 2 (close to the lower 


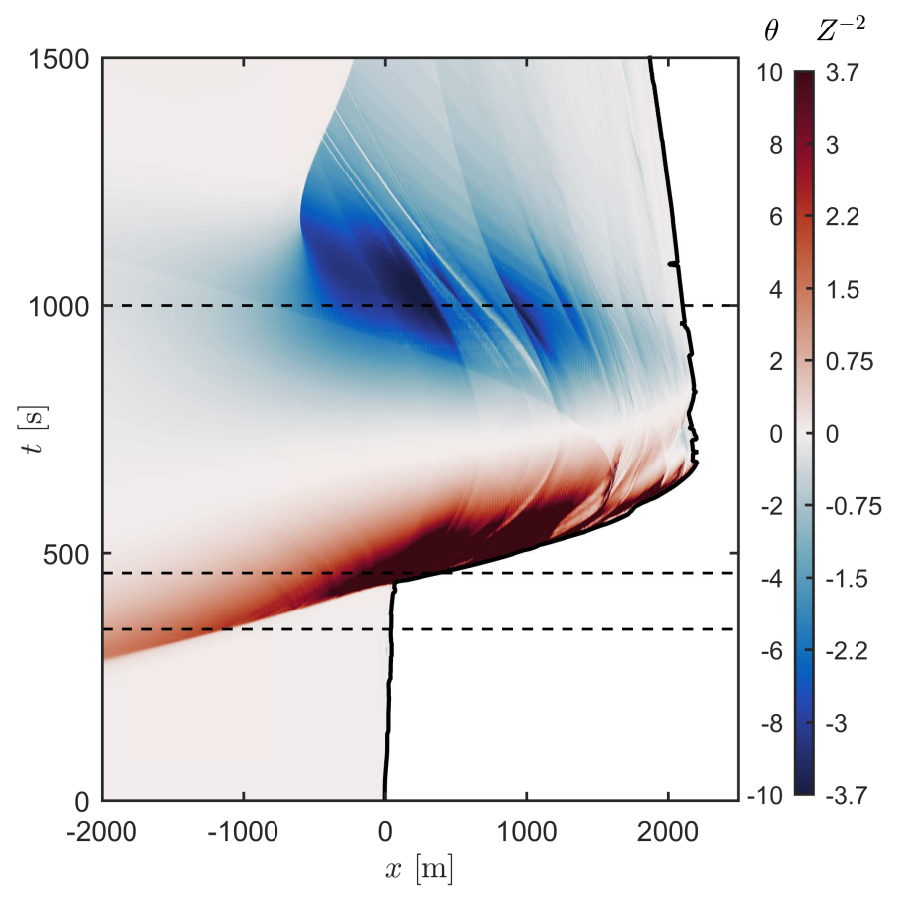

Figure 2: Shields parameter, $\theta$ and inverse of the Rouse parameter squared $Z^{-2}$ as a function of $x$ and $t$ for case S200. The horizontal dashed lines corresponds to the instants shown in Figure 3. The maximum and minimum $\theta$ for this case are 258 and -122 , respectively.

dashed line), and the wave front can easily be identified by the very large gradient in either $\theta$ or $Z^{-2}$ with respect to time. Behind the wave front $\theta$ decreases. This is due to the decreasing velocity, but also, as will be shown in the forthcoming sections, due to the boundary layer increasing behind the tsunami front. This reduces the velocity gradients and in turn the bed shear stresses. During shoaling $\theta$ is already high and $Z^{-2}>0.25$ for most of the wave front meaning that sediment can be expected to be transported largely in suspension. It is important to stress that the boundary layer may or may not span the entire water depth, as will be discussed in the following section. Thus even in cases with very high $Z^{-2}$, the suspended sediment may not necessarily span across the entire depth. It should be noted that the tsunami is much longer (approximately $9 \mathrm{~km}$ ) than shown in Figure 3a, and further behind the tsunami front $Z^{-2}<0.25$ meaning that bed load transport would likely be the most important transport mechanism.

While inundating, the velocities increase further as seen in Figure $3 \mathrm{~b}$. 


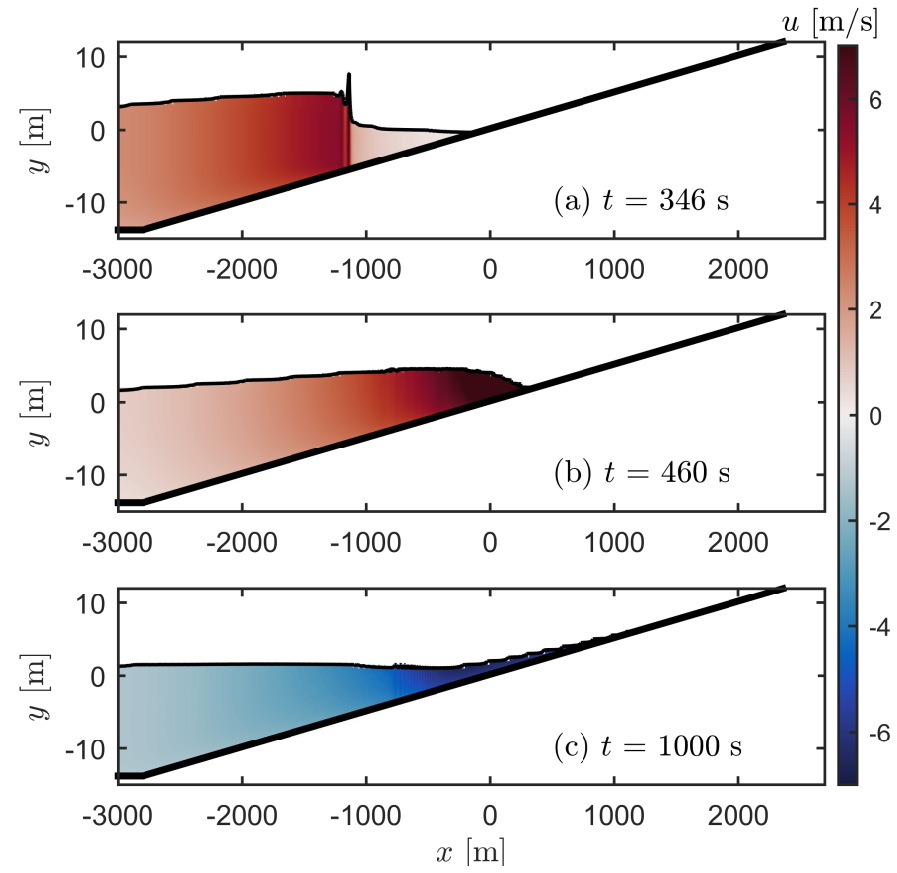

Figure 3: Surface elevations and velocities of case S200 at different times.

This results in significantly higher $\theta$ as seen in Figure 2 (near the dashed line in the middle). Near the front $\theta$ reaches $\mathrm{O}(100)$ (though the colorscale has been limited to $-10<\theta<10$ to make the figure more readable). On the other hand, $Z^{-2}$ reaches $\mathrm{O}(10)$, which indicates that the suspended sediment will be present to a large degree throughout the boundary layer. Behind the breaking tsunami front $Z^{-2}$ is decreasing meaning that suspended sediment will likely be more and more confined to the lower part of the tsunamiinduced boundary layer. From Figure 2 it can also be seen that during inundation the horizontal span with large Shields parameters widens compared to the shoaling situation. The reason for this is that the depth is lower (causing larger shear), but also that the boundary layer here (as will be shown in the Section 3.2) spans the entire depth. Therefore there will not be large differences in the near bed velocity gradients at the tip of the tsunami front and some distance behind it. It is worth noting that during inundation larger regions with significantly lower $\theta$ and $Z^{-2}$ are present around $x \approx 1500 \mathrm{~m}$ and $t \approx 600 \mathrm{~s}$. These regions occur due to undulations in the surface elevation in the front of the breaking bore. This appears to be similar to the process described in $\mathrm{Lu}$ et al. (2018), where new bores 
developed at the bore front in a model scale experiment. In the vertical the difference in surface elevation of these undulations is not well resolved (only by approximately 5 cells), but this is still enough cells that we believe it to be a physical phenomenon.

While receding (Figure 3c and near the upper dashed line in Figure 2) it can be seen that the magnitudes of the velocities and resulting $\theta$ values are somewhat lower than those near the breaking tsunami front. It can however be seen that high-magnitude $\theta$ values are present over a much longer span $(>2 \mathrm{~km}$ as can also be seen from Figure 2). This can be explained by the water depth being much lower compared to the height of the tsunami front, and as a result vertical velocity gradients and shear stresses become larger. This results in a much broader region with high $Z^{-2}$, meaning that the sediment transport during the draw-down would again also seemingly be characterized to a high degree by suspended sediment load. It is worth noting the whitish lines/streaks which appear during recession $(x \approx 0-$ $1000 \mathrm{~m}$ and $t \approx 700-1200 \mathrm{~s})$. These appear to be related mixture of air and water in the vicinity of the bed. This mixture locally enhances turbulent production and cause variations in the velocities. These mixtures were generated during the breaking and have a difficulties escaping due to the simulations being two-dimensional. The mixture regions are only $\mathrm{O}(\mathrm{cm})$ in the vertical (a few cells thin), but often span several meters (the cells are $0.5 \mathrm{~m}$ long). This is due to the large aspect ratios of the bottom boundary layer cells. The whitish while receding is therefore believed to be a numerical artefact caused by the two dimensional simulation and large aspect ratios. Though unfortunate, we dot believe that these streaks significantly affect the overall run-up and draw-down process and thereby the conclusions drawn in the current paper.

The $\theta$ values and $Z^{-2}$ values will also naturally depend on how the tsunami runs-up. To demonstrate other characteristic scenarios, we will now show results for two additional cases, namely case S030 and case N100 (Table 1). These were chosen to also demonstrate the results in cases where the tsunami is not breaking (case S030, categorized as surging, see Part 1) or has a leading depression (case N100) which runs up as a breaking bore similar to case S200 (see Part 1 for the a detailed description of the run-up of breaking bores).

Figure 4 shows the Shields, $\theta$ and inverse Rouse parameter squared $Z^{-2}$ as a function of both time and space for case S030, which is a single wave running up a slope of $S=1 / 30$, and Figure 5 shows surface elevations and velocities at three different instants. The times were again selected to show the tsunami during shoaling (Figure 5a), inundation (Figure 5b) and 
draw-down (Figure 5c). While shoaling the tsunami wave front is not

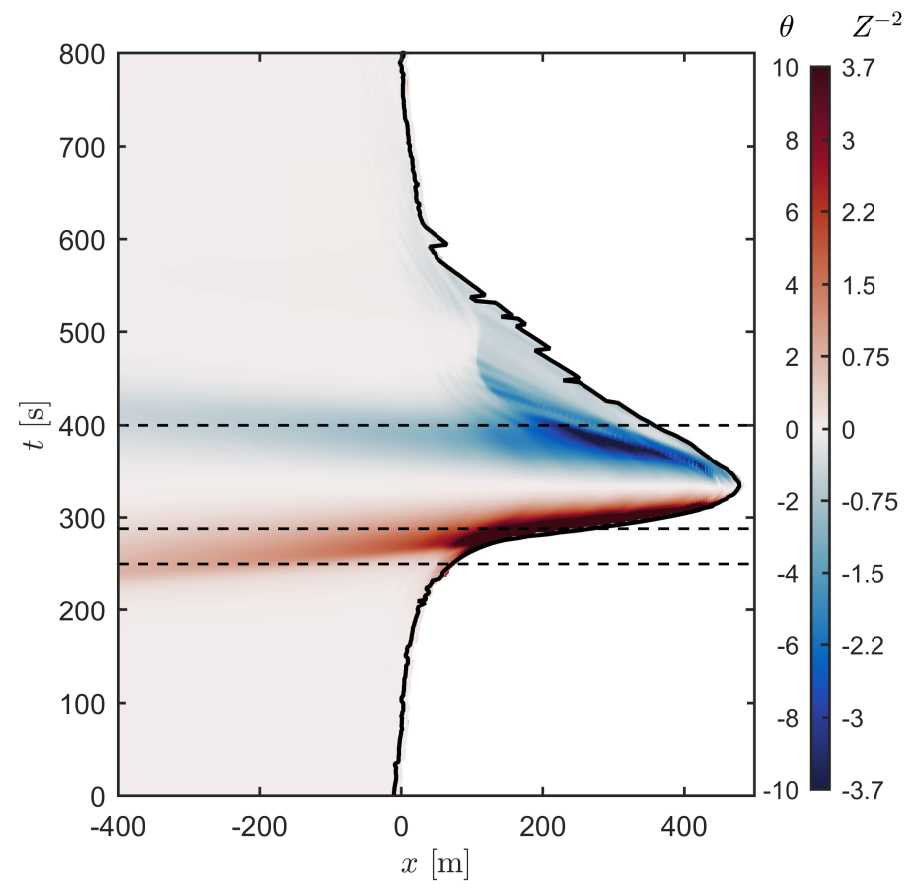

Figure 4: Shields parameter, $\theta$ and inverse of the Rouse parameter squared, $Z^{-2}$ as a function of $x$ and $t$ for case S030. The horizontal dashed lines corresponds to the instants shown in Figure 5. The maximum and minimum $\theta$ for this case are 123 and -12 , respectively.

very steep, as seen in Figure 5a. This results in lower velocities, and as a result also lower $\theta$ values compared to case S200 (Figure 4 compared to Figure 2 near the lower dashed lines). As a result $Z^{-2}<1$ is generally the case while shoaling. As $Z^{-2}>0.252$, this still means that sediment will likely be transported in suspension, but due to the lower values relative to those from case S200 the sediment would not be expected to be as uniformly distributed across the boundary layer, and would likely be more confined to the bottom part of the boundary layer. During inundation (Figure $5 \mathrm{~b}$ and 4 near the middle dashed line) it can be seen that the tsunami wave front has accelerated significantly and the velocities and resulting $\theta$ values here are similar in size to the front of case S200 during inundation (Figure $3 \mathrm{~b}$ and 2 near the middle dashed line), as are the $Z^{-2}$ values, which are larger than 0.25 all the way to the toe of the slope. Similar to case S200, it can be seen that while receding (Figure $5 \mathrm{c}$ and near the top dashed lines in Figure 4) $\theta$ 


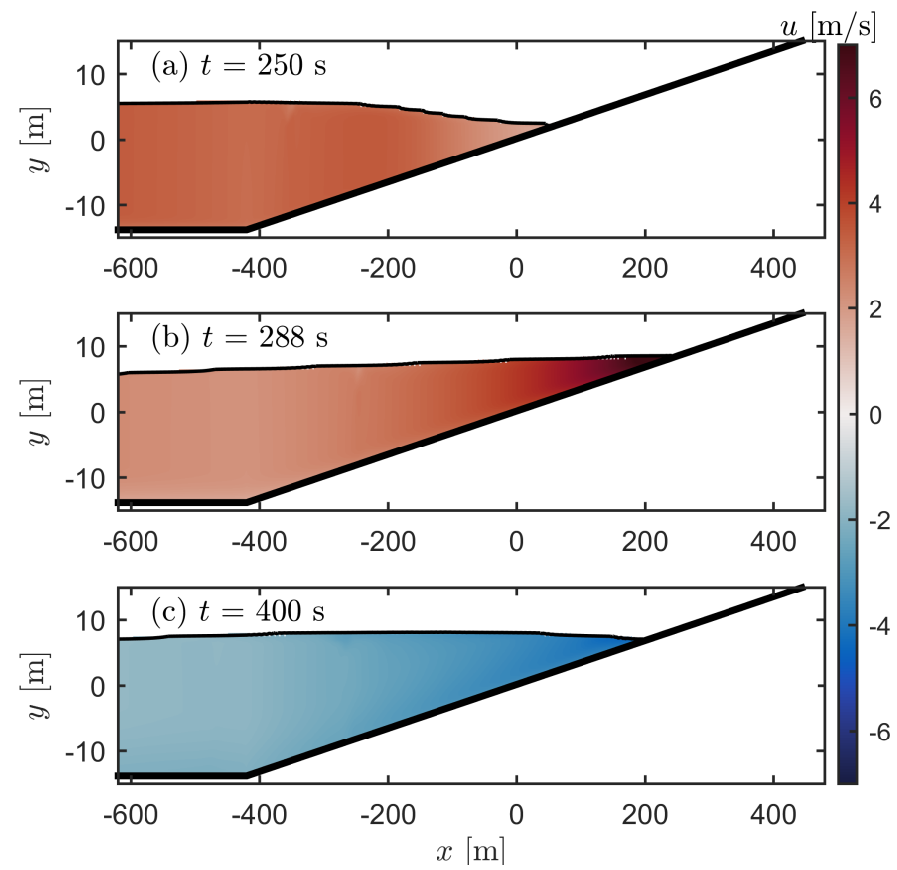

Figure 5: Surface elevations and velocities of case S030 at different times.

does not reach such large extreme values as near the front of the tsunami. Values exceeding unity are still observed all the way to the toe of the slope, again indicating significant sediment transport also during draw-down.

Finally, in Figure $6 \theta$ and $Z^{-2}$ are shown as a function of space and time for case N100, which is a leading depression N-wave running up a slope of $S=1 / 100$, and Figure 7 shows surface elevations and velocities at three different instants (during shoaling Figure 7a, inundation Figure 7 and draw-down Figure 7c). The leading depression can easily be seen from the shoaling position in Figure 6a. Here regions with lower surface elevations and negative velocities are clearly visible in front of the tsunami wave front. This can likewise be seen in Figure 6 where the shoreline has moved offshore (negative $x$ ). Similar to case S200, the front of the tsunami has split during shoaling, and a few shorter waves can be seen riding on the main tsunami wave front. Also similar to case S200, these shorter waves cannot sustain their shape during shoaling, and break some distance from the shore. The resulting Shields parameter near the crest of the shoaling tsunami is high (Figure 6 near the bottom dashed line), but not as high as in case S200 (Figure 2 near the bottom dashed line), where a significantly larger wave 


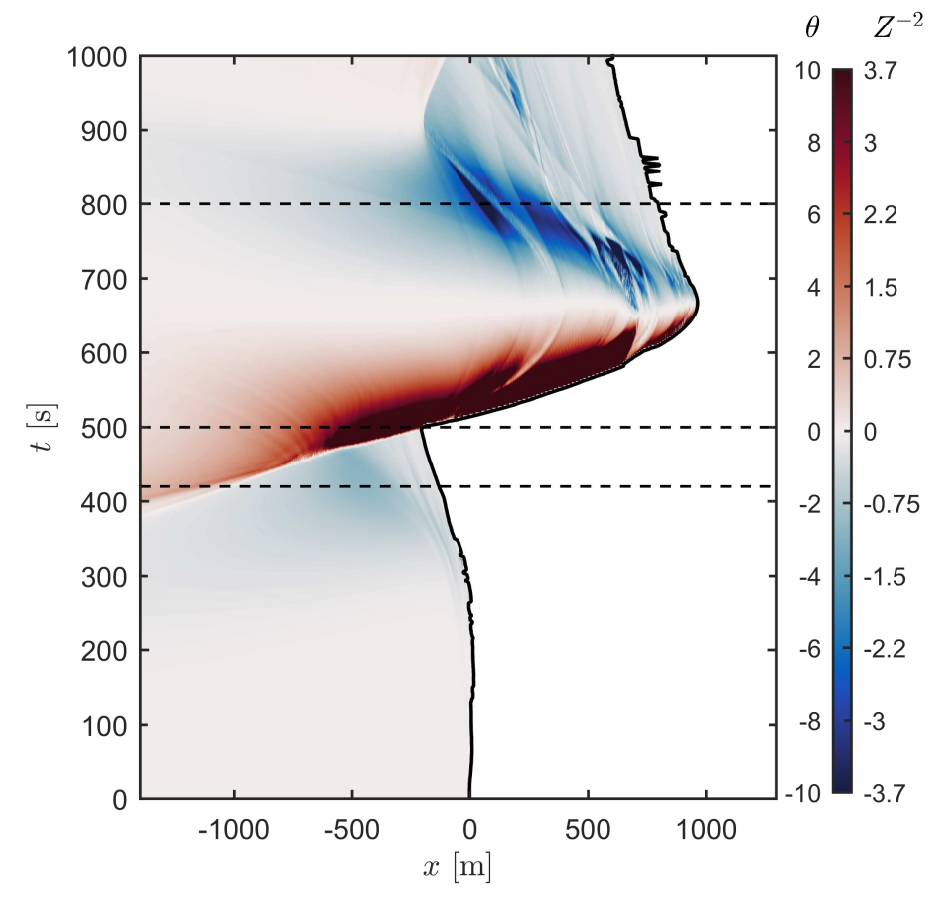

Figure 6: Shields parameter, $\theta$ and inverse of the Rouse parameter squared, $Z^{-2}$ as a function of $x$ and $t$ for case N100. The horizontal dashed lines corresponds to the instants shown in Figure 7. The maximum and minimum $\theta$ for this case are 185 and -29 , respectively.

front was present. It can also be seen that the leading depression, causing the shoreline to retreat, has the potential to move significant amounts of sediment as the magnitude of $\theta$ is generally larger than one.

During inundation (Figure $7 \mathrm{~b}$ and near the middle dashed line in Figure 6) and draw-down (Figure 7c and near the top dashed line in Figure 6 ) the image is very similar to the two previous cases. Here, the front of the inundating tsunami has very high $\theta$ and $Z^{-2}$, indicating significant sediment transport as well as significant amount of sediment transported in suspension. During draw-down $\theta$ and $Z^{-2}$ are again generally high indicating likely significant suspended sediment transport during draw-down. Similar to case S200 some whitish lines/streaks appear in $\theta$ and $Z^{-2}$. This is again explained by undulations in front of the wave during run-up as well as a mixture of air and water in the vicinity of the bed during recession. Additionally, in this case the scar-like features seen during recession around $x \approx 400-600 \mathrm{~m}$ and $t \approx 700-900 \mathrm{~s}$ are believed to come from the wa- 

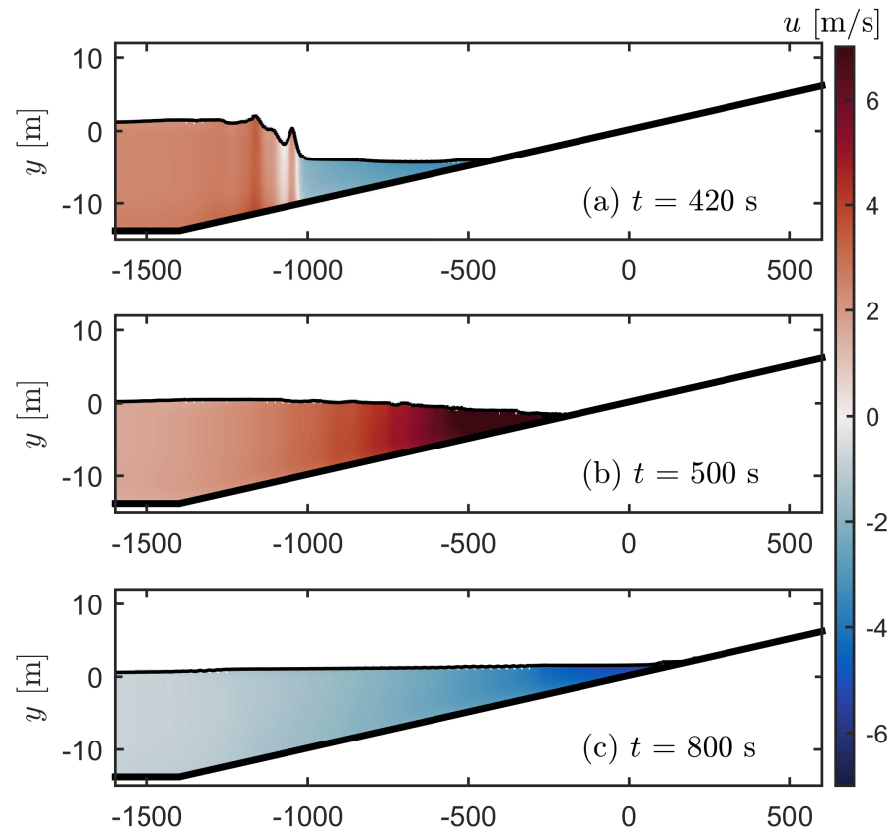

Figure 7: Surface elevations and velocities of case N100 at different times.

ter depth not decreasing monotonically towards the shore. Shorter waves are generated due to the complex run-up and when these shorter waves run down it causes variations in both velocities and bed shear stresses.

Tsunamis of the size considered in the present work, clearly have the potential to move a considerable amount of sediment. The largest magnitude $\theta$ are seen at the tsunami front while inundating, indicating highest sediment transport rates here. Generally the $Z^{-2}$ values in the considered cases were so high that the sediment transport would be expected to be dominated by suspension. At the front of the inundating tsunami $Z^{-2}$ where even higher, such that suspended sediment could be expected to be present throughout the boundary layer and potentially mixed further via any breaking waves.

The results presented here can help assess the assumptions commonly used by inverse paleo tsunami models. In the models by Moore et al. (2007), Soulsby et al. (2007) and Jaffe and Gelfenbuam (2007) it was assumed that sediment was transported only during run-up, and not re-suspended during draw-down. As just shown, during the draw-down phase, suspended sediment transport can be expected to be present to a large degree. It should be stated, however, that the present tsunami cases can all be considered to 
be rather large events, and smaller tsunamis would naturally have less sediment transport potential. It should also be stated that the current setup has a constant slope whereas the field will have significantly more complex topographies. Jaffe and Gelfenbuam (2007) argues that the tsunami will have a tendency to draw-down in topographic low areas and thereby not carry much of the deposited sediment. The Shields parameters during draw-down are large, but generally slightly lower than those present near the tsunami wave front. If the sediment was comprised of widely varying grain sizes, this would mean that the largest grains, which could be carried by the tsunami wave front will not necessarily move during draw-down, and the assumption that sediment will not be re-suspended during draw-down may, in some cases, be more reasonable for the largest grains in a sample. This scenario would mean that deposits will not to tend to have smaller grain sizes moving inland (deposits fining inland), as assumed by many inverse models, as the finer sediments would be re-suspended and be drawn seaward, while the coarser sediments would remain. This is similar, in fact, to the experimental finding by Yoshii et al. (2017).

As mentioned previously the conclusions drawn here, are based on one assumed grain type. Assuming other grain sizes would mostly affect when and where sediment is expected to travel in suspension and how uniformly it would be distributed within the boundary layer. As $Z^{-2}$ in three cases are significantly above the threshold for when sediment go into suspension during large parts of both the run-up and draw down, it would require significantly larger grains (probably gravel type) to alter this conclusion, however. In contrast, assuming finer grains would mean that sediment could be expected to travel in suspension and be more uniformly distributed for even larger parts of the tsunami events.

\subsection{Boundary layers}

In this section we will focus on the tsunami induced-boundary layers that develop during the CFD simulations. For brevity, we will not go into detail on all three cases. Rather, we will discuss in detail the tsunami-induced boundary layer of case S200 which can be considered as a typical example of the simulated cases. Result of boundary layer thickness and friction velocity of the two remaining cases (S030 and N100) will be shown to supplement the analysis. 

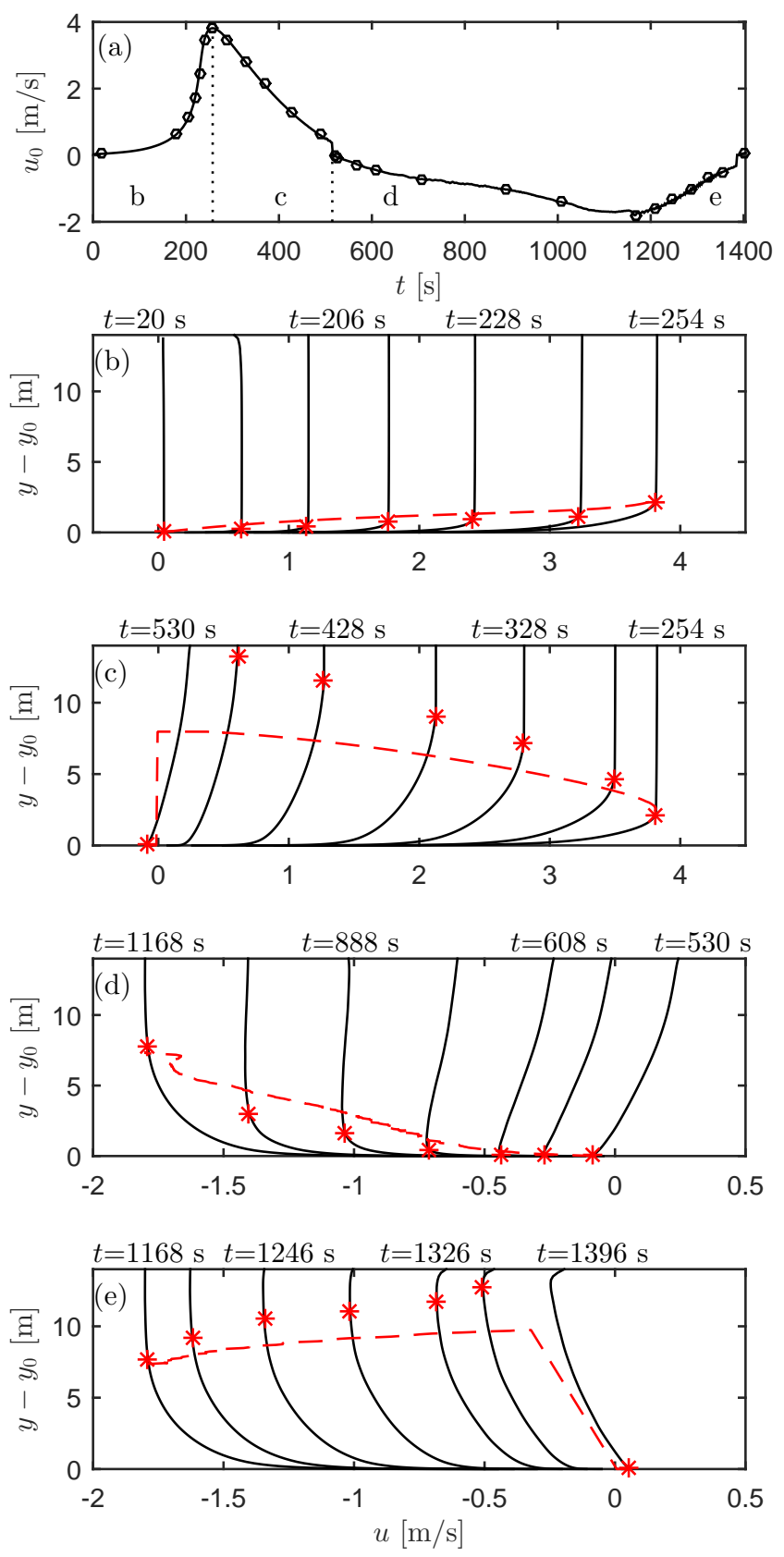

Figure 8: (a) free-stream velocity signal where (:) and (o) marks the separation between the phases and times for the velocity profiles shown in (b)-(e) and (b)-(e) Modelled velocity profiles (-), modelled boundary layer thickness $(*)$, predicted from (8) boundary layer thickness (- -) for case S200 at the toe of the slope $(x=-2800 \mathrm{~m})$. 
Figure 8 shows the free-stream velocity signal (Figure 8a) as well as the velocity profiles (Figure 8b-e) at different times for case S200 at the toe of the slope $(x=-2800 \mathrm{~m})$. Included in the figure as asterisks are also the modelled boundary layer thickness $\delta$, which has been estimated as the lowest vertical position where

$$
\frac{y-y_{0}}{|u|} \frac{\partial|u|}{\partial y}<0.03
$$

Here $y_{0}$ is the bed elevation. If the above is not fulfilled at any position the boundary layer thickness is simply taken as the water depth. This is somewhat different from the standard way of estimating boundary layer thickness, which is sometimes taken as the vertical position where $u<0.99 u_{0}, u_{0}$ being free stream velocity. From the modelled results, however, it was difficult to estimate $u_{0}$, as the crest of the steep waves sometimes had higher velocities than the near bed flow. Overcoming this difficulty therefore led to the above formulation, and as can be seen from Figure 8, the modelled boundary layer thicknesses defined using (6) corresponds well with visual expectations. The threshold of 0.03 was chosen as the lowest value not causing large frequent oscillations in the calculated boundary layer thickness. A lower value would have the calculated boundary layer thickness suddenly jumping to water depth as the threshold was not met. For the remainder of this study $u_{0}$ is defined as the velocity at $y=y_{0}+\delta$.

Williams and Fuhrman (2016) proposed that the boundary layer thickness beneath the peak flow in a tsunami could be predicted by

$$
\frac{\delta}{a}=0.05\left(\frac{a}{k_{s}}\right)^{-0.11} \quad \text { or } \quad \delta=0.05 a^{0.89} k_{s}^{0.11}
$$

where $a=U_{m} / \Omega$ is the amplitude of the orbital motion and $U_{m}$ is the maximum free-stream velocity. As we would like to predict the time varying boundary layer thickness, we propose to extend this formula such that

$$
\delta(t)=\min \left(0.05 a(t)^{0.89} k_{s}^{0.11}, h\right)
$$

The first argument is similar to (7) and the second argument ensures that the predicted boundary layer thickness will not exceed the local water depth. In (8) $a=U_{m} / \Omega$ has been replaced with

$$
a(t)=\int_{t_{0}}^{t}\left|u_{0}(t)\right| d t
$$


where $t_{0}$ is the time of the previous zero crossing of the free stream velocity. $a(t)$ is then a measure of the distance travelled by a free-stream particle following flow reversal. This definition of $a(t)$ will for the standard sinusoidal wave case give the same boundary layer thickness at the peak velocity as the formulation by Williams and Fuhrman (2016). The predicted value for the (now time varying) boundary layer thickness using (8) is included in the figure as a dashed line.

The flow during first acceleration phase is shown in Figure 8b, the subsequent deceleration phase in Figure 8c, the second acceleration phase, which is the tsunami drawing down in Figure 8d, and finally the second deceleration phase in Figure 8e.

During the first acceleration phase (Figure 8b) and the first deceleration phase (Figure 8c) it can be seen that the boundary layer continually grows. It starts as only a small fraction of the water depth, but grows nearly to the free surface by the end of the first deceleration phase. This supports the results by Williams and Fuhrman (2016) which highlighted that the tsunamiinduced boundary layers may be both wave-like and current-like. During the draw-down (Figure 8d-e) it can be seen that the boundary layer grows both during the acceleration and deceleration phases. It can also be seen that the predicted boundary layer thickness from (8) agrees well during the acceleration phase, but slightly under-predicts the boundary layer thickness during the deceleration phase. In Figure $8 d$ a small oscillation can be seen in dashed line towards the end of the acceleration phase. This caused by a very small decrease in the free-stream velocity between $t=1120-1150 \mathrm{~s}$ velocity as seen in Figure 8 which comes from very small differences in the free-surface. 

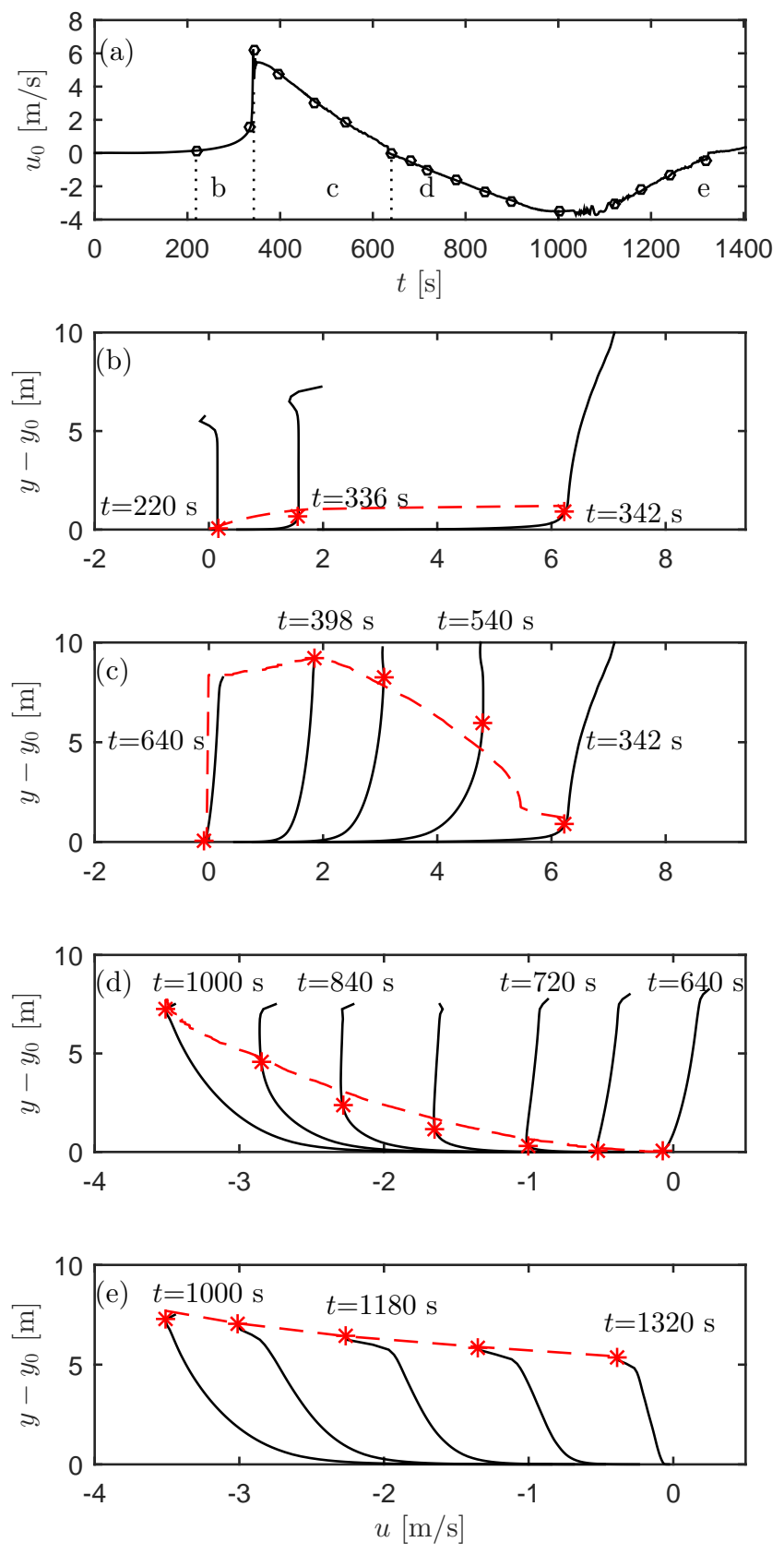

Figure 9: (a) free-stream velocity signal where (:) and (o) marks the separation between the phases and times for the velocity profiles shown in (b)-(e) and (b)-(e) Modelled velocity profiles (-), modelled boundary layer thickness $(*)$, predicted from (8) boundary layer thickness (- -) for case S200 in a shoaling position $(x=-1200 \mathrm{~m})$. 
455 When the tsunami shoals, the wave front steepens and velocities increase, 456 as seen in Figure 3a. Figure 9 shows the free-stream velocity (Figure 9a) and 457 the velocity profiles (Figure 9b-e) of the now-shoaled wave at $x=-1200$

$458 \mathrm{~m}$ now corresponding to a water depth of $h=6 \mathrm{~m}$. Included in the figure 459 is also the modelled and predicted boundary layer thickness, similar to be-

fore. During the first acceleration phase (Figure 9b) it can be seen that the initial acceleration is is not that large but from $t=336 \mathrm{~s}$ to $t=348 \mathrm{~s}$ the wave accelerates from approximately $2 \mathrm{~m} / \mathrm{s}$ to approximately $6 \mathrm{~m} / \mathrm{s}$. This corresponds to the arrival of the very steep wave front. Due to the very large acceleration, the boundary layer barely has time to grow, and at the peak velocity the boundary layer thickness is only around $1 \mathrm{~m}$ high. This development is well predicted by equation (8), shown as the dashed line. During the subsequent deceleration (Figure 9c) the boundary layer grows all the way to the free surface, which is also captured by (8). During the draw-down (Figure 9d) a new boundary layer forms. Here the water depth is almost constant, and the boundary layer eventually stretches all the way to the free surface. In the deceleration phase of the draw-down (Figure 9e), the boundary layer remains depth limited. Again an excellent agreement between the modelled and predicted boundary layer thickness is achieved. 

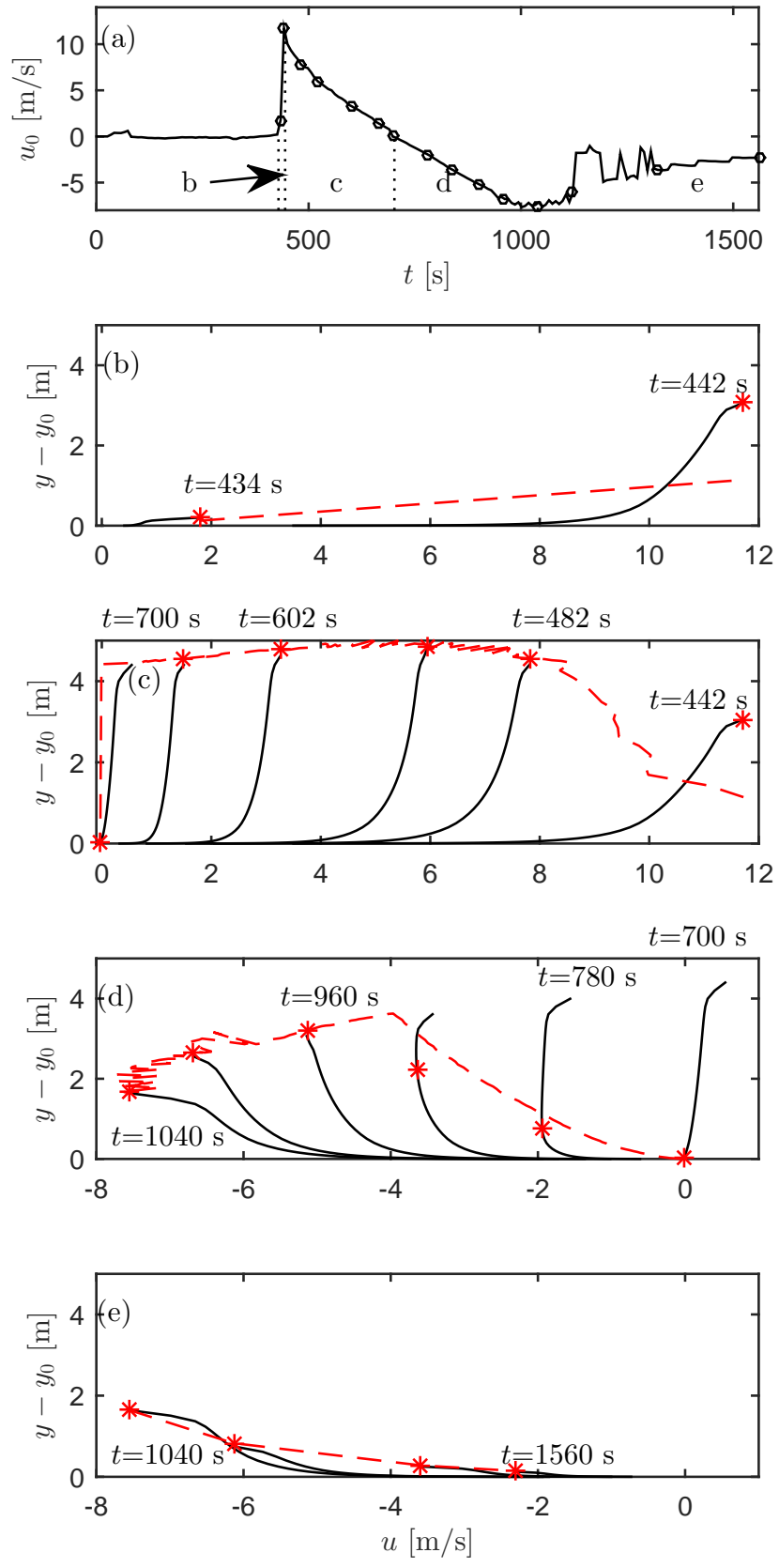

Figure 10: (a) free-stream velocity signal where (:) and (o) marks the separation between the phases and times for the velocity profiles shown in (b)-(e) and (b)-(e) Modelled velocity profiles (-), modelled boundary layer thickness $\left(^{*}\right)$, predicted from (8) boundary layer thickness (- -) for case S200 at the shore $(x=0 \mathrm{~m})$. 
When the tsunami hits the coast it becomes even steeper than at the shoaling position, and the front of the tsunami is breaking as seen in Figure 3b. Figure 10 shows the free-stream velocity (Figure 10a) and the velocity profiles (Figure 10b-e) at the original shoreline $(x=0 \mathrm{~m})$. Included in the figure is also the modelled and predicted boundary layer thickness, similar to before. As a result of the increased steepness the initial acceleration phase is only approximately $1 \%$ of the period, where it accelerates from zero to 12 $\mathrm{m} / \mathrm{s}$ in just $8 \mathrm{~s}$, as seen in Figure 10b. In this case the wave is running up like a breaking bore, and the boundary layers are essentially at all times limited by the water depth. This behaviour is not captured by (8), but as can be seen during the subsequent longer deceleration phase (Figure 10c), due to the high velocities, this expression quickly predicts that the boundary layer will extend all the way to the free-surface, similar to the modelled results. Similar to the shoaling position, Figure 10d shows that a new boundary layer is forming during the acceleration phase of the draw-down, and this boundary layer eventually reaches the free-surface. During the latter stages of this acceleration phase oscillations in the dashed line can be seen. At this stage boundary layers is depth limited and the oscillations are due to varying velocities in the top most cell which contain a mixture of air and water and might be slightly affected by air velocities. During the final deceleration stage (Figure 10e), the boundary layer remains limited by the water depth, which slowly declines towards zero.

It is worth noting that the velocity profiles during run-up and draw-down are very sheared. This is similar to the velocity profiles from O'Donoghue et al. (2010) for the run-up and draw-down of a bore in hydraulically rough conditions. The sheared velocity profiles might be important for impact forces by floating debris which depending on geometry and buoyancy will be affected very differently by this sheared flow.

In some studies logarithmic velocity profiles spanning the entire depth have been assumed, see e.g. Kuriyama et al. (2014) and Sugawara et al. (2014b). This assumption was partially backed up by Lacy et al. (2012), who showed a clear logarithmic profile beneath the 2010 Chilean tsunami (measured outside the coast of California), though this logarithmic profile only spanned a small fraction of the water depth. To demonstrate the appearance of the tsunami-induced boundary layers Figure 8a,b and Figure 9a,b are re-plotted now using a logarithmic vertical scale in Figure 11. This shows the velocity profiles during the first acceleration and deceleration phase from case S200 at both the toe of the slope at $x=-2800 \mathrm{~m}$ (Figure 11a,b) and in the shoaling position at $x=-1200 \mathrm{~m}$ (Figure 11c,d). Figure 11 clearly illustrates that the computed tsunami-induced boundary 

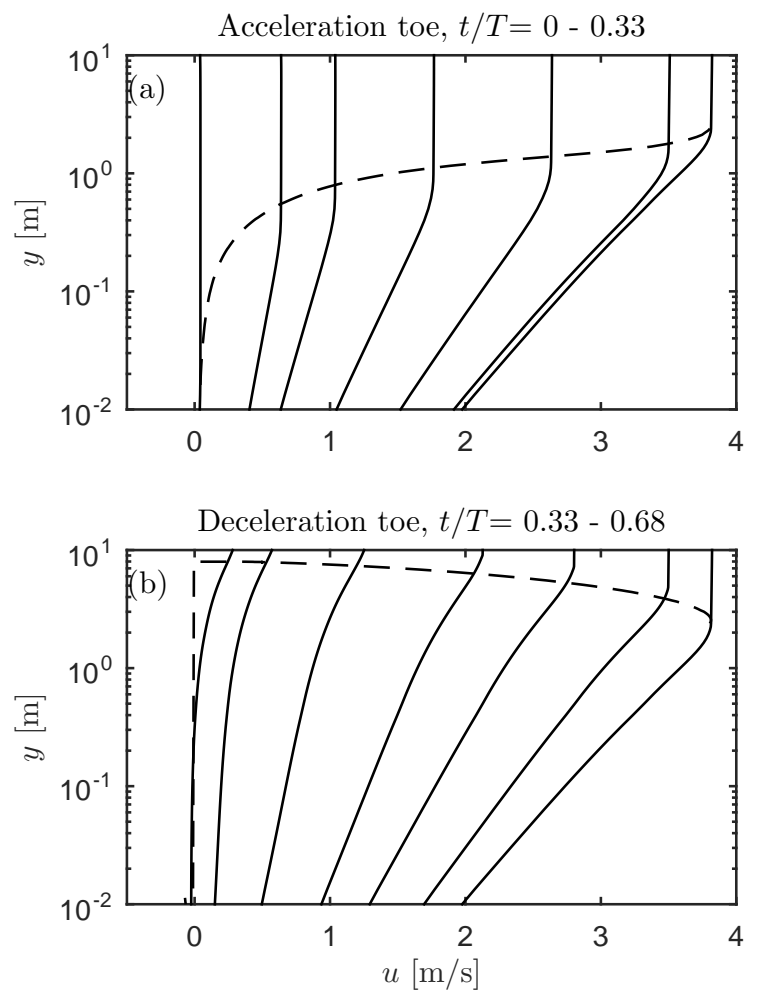
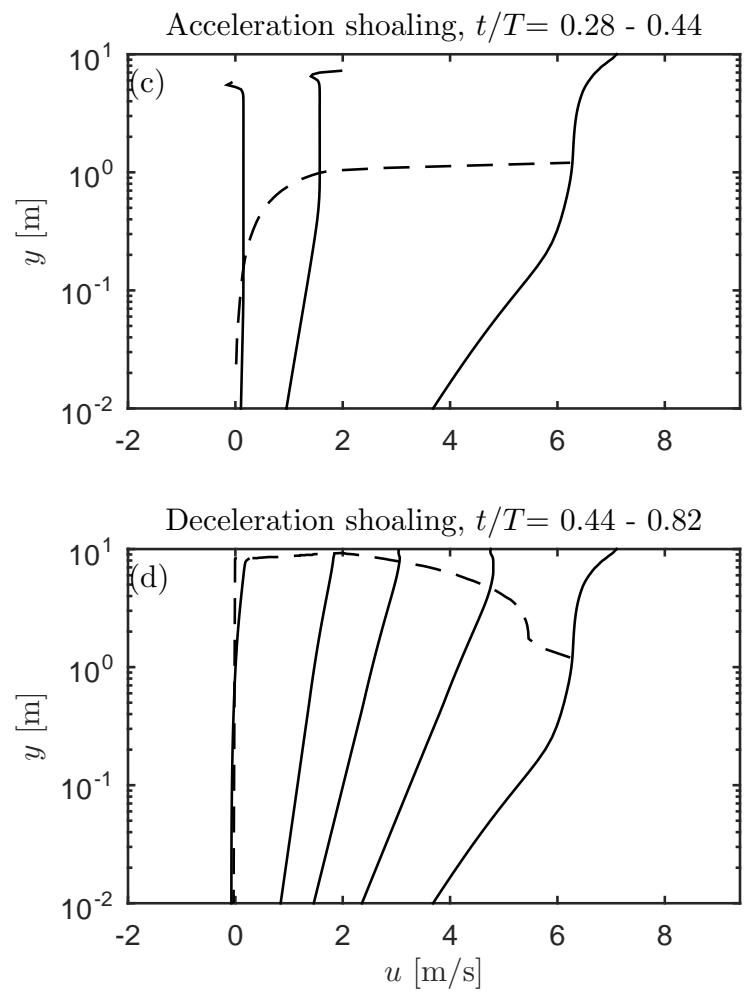

Figure 11: Modelled velocity profiles (-) and predicted boundary layer thickness (8) (- -) for case S200 at (a),(b) $x=-2800 \mathrm{~m}$ and (c),(d) $x=-1200 \mathrm{~m}$.

520

521

522

523

524

525

526

527

layers are indeed logarithmic, as nearly perfect straight lines near the bed are shown. The results, however, also indicate that the velocity profiles do not follow a logarithmic profile all the way to the free-surface, but rather a limited part of the water depth. It can likewise be seen that (8) depicted as a dashed line, gives a reasonable approximation for the region where the velocity profiles are logarithmic. This is typical for all the cases simulated. This indicates that assumed logarithmic velocity profiles could work reasonlogarithmic profile will therefore probably not be a good assumption. Above the line given by (8) the velocity profiles might be uniform as was the case at the toe (Figure 11a,b) or they be further sheared as a consequence of breaking, very steep wave front or shorter dispersive waves as in the shoaling position (Figure 11c,d). 


\subsection{Predicting the bed shear stress/friction velocity}

With the good agreement between the modelled and predicted time varying boundary layer thickness, it seems obvious to extend this approach to likewise predict the bed shear stress (or friction velocity), which is often regarded as the primary factor governing sediment transport. Williams and Fuhrman (2016) showed that standard wave friction factor expressions also applied reasonably to the tsunami-scale waves at peak flow. We therefore suggest the following simple engineering model to predict the friction velocity beneath tsunami waves:

$$
U_{f}(t)=\sqrt{\frac{\tau_{0}}{\rho}}=\sqrt{\frac{f(t)}{2}} u_{0}(t)
$$

where $\tau_{0}$ is the bed shear stress, $\rho$ is the water density and $f(t)$ is a time varying friction factor. Another variant of a time varying friction factor approach has also been used by Gonzalez-Rodriguez and Madsen (2007), see Appendix A for more details. For hydraulically rough flows, the constant friction factor is traditionally given as a function of $a / k_{s}$. There exist many formulae for the friction factor as a function of $a / k_{s}$, see e.g. Fredsøe and Deigaard (1992), Nielsen (1992) or Fuhrman et al. (2013). In what follows, we will utilize the expression from Fuhrman et al. (2013), but again substituting $a$ with $a(t)$ from (9), leading to the following time-varying wave friction factor:

$$
f_{w}(t)=\exp \left(5.5\left(\max \left(\frac{a(t)}{k_{s}}, 1\right)\right)^{-0.16}-6.7\right)
$$

From this equation it can be seen that large orbital free stream motion will lead to smaller friction factors. The reason for this is that the boundary layer will have longer time to grow, and thus the velocity gradients become smaller. A max condition on $a(t) / k_{s}$ has been introduced to handle the singularity as well as limit the friction factor for very small values of $a(t) / k_{s}$. In addition to this, it is important to recognize (as just shown) that the tsunami boundary layer may extend all the way to the free surface, and at this stage it would be more current-like. Therefore, to also account for this possibility we define $f(t)$ generally as

$$
f(t)=\max \left(f_{w}(t), f_{c}\right)
$$


where $f_{c}$ is the current friction factor given by the Colebrook-White formula

$$
f_{c}=\frac{2}{\left(C-2.5 \log \left(k_{s} / h\right)\right)^{2}}
$$

with $C=8.5$. The change from the traditional coefficient $C=6.5$ from Colebrook and White to $C=8.5$ is because the present formulation is based on the free-stream velocity $\left(u_{0}=u(y=\delta)\right.$ i.e. at the top of the boundary layer) rather than the depth-averaged velocity. The above formulation ensures a continuous transition to a current-based friction factor at positions where the boundary layer extends all the way to the free-surface. Note that the model described above may also be utilized in conjunction with depthaveraged velocities e.g from NLSW models, by instead setting $C=6.5$. Additionally, for comparison, we will also estimate the friction velocity by what we will deem a standard approach for NLSW models. In the literature different approaches have been used. Kuriyama et al. (2014) and Cheng and Weiss (2013) e.g. used an assumed logarithmic profile spanning the entire depth and Yamashita et al. (2016) as well as Li et al. (2012) used a Manning approach. Here we will compare with the Manning approach, where the friction velocity for the present cases can alternatively be calculated as

$$
U_{f}=\langle U\rangle n h^{-1 / 6} \sqrt{g}
$$

where

$$
\langle U\rangle=\frac{1}{h} \int_{y_{b}}^{\eta} u d y
$$

is the depth-averaged velocity and $n$ is the Manning coefficient, which in what follows has been calculated by

$$
n=\frac{k_{s}^{1 / 6}}{8.1 \sqrt{g}}=0.0125 \frac{\mathrm{s}}{\mathrm{m}^{1 / 3}}
$$

We will now compare the predicted time variation of the friction velocity using both the new engineering approach and the Manning approach for cases N100 and S030. We will likewise compare the modelled and predicted boundary layer thickness to illustrate the performance of (8) for two additional cases.

Figure 12 shows free-stream velocities (Figure 12a-c), surface elevations, modelled- and predicted boundary layer thickness (Figure 12d-f) as well as friction velocities using both the present engineering approach and the Manning approach (Figure 12g-i) for case N100 at the toe of the slope $(x=$ 
$-1400 \mathrm{~m})$, at a shoaling position $(x=-900 \mathrm{~m}$,$) and at the shore (x=0$ $\mathrm{m})$. For the Manning approach we have used the calculated free-stream velocity rather than the depth-averaged velocity. The difference between the depth-averaged and free-stream velocity is small, although using the depthaveraged velocity resulted in slightly lower friction velocity predictions than are presented here.

Figure $12 \mathrm{~g}$-i shows the friction velocity being lowest at the toe of slope and highest at the shore. This is both due to an increased velocity as the wave shoals (see the increasing free stream velocity in Figure 12a-c), but also an increased asymmetry, resulting in smaller boundary layer thickness and higher velocity gradients. The predicted friction velocity using both the Manning approach (14) as well as the engineering model (10) follows the shape of the modelled friction velocity. There is, however, a tendency to under-predict the magnitude of the friction velocity using the Manning approach at the toe of the slope and in the shoaling position. This can be explained by the Manning approach not capturing the effect of the time varying boundary layer thickness, which at these positions only spans a small fraction of the water depth, when the front of the tsunami arrives (Figure $12 \mathrm{~g}-\mathrm{h})$. This physical feature, by design, seems to be well captured by the present approach based on (10). It can also be seen that (8), in general, does a consistently good job of predicting the time varying boundary layer thickness for case N100. The largest discrepancies are found at the shoaling position during the second and third deceleration phases (Figure 12e, $t=$ $430-670 \mathrm{~s}$ and $t=900-950 \mathrm{~s}$ ).

Figure 13 shows free-stream velocities (Figure 13a-c), surface elevations as well as modelled- and predicted boundary layer thickness (Figure 13d-f) and modelled friction velocities as well as predicted friction velocities using both the present engineering approach and the Manning approach (Figure $13 \mathrm{~g}-\mathrm{i})$. These are shown for case S030 at the toe of the slope $(x=-420 \mathrm{~m})$, at a shoaling position $(x=-180 \mathrm{~m}$,$) and at the shore (x=0 \mathrm{~m})$. Similar to before both the present engineering model and the Manning approach follow the shape of the computed friction velocity (Figure 13g-i), but again there is a tendency to under-predict the magnitude of the friction velocity using the Manning approach at the toe of the slope and at the shoaling position (Figure 13g,h). The proposed engineering model again captures this effect. It is also worth noting, that in this case, where the wave is not breaking, the boundary layer only stretches the entire depth during the deceleration phase of the draw-down at the shoaling position (Figure 13e, $t=550-800$

s) as well as the deceleration phase of the draw-down at the shore (Figure 13f, $t=430-600 \mathrm{~s})$. This indicates that the tsunami-induced boundary 
layer is very dependent on the run-up type. Finally, it can be seen from Figure 13d-f that the match between the modelled boundary layer thickness and that predicted by (8) is again reasonable.

To demonstrate further the performance of the proposed engineering model and the difference between this and the standard Manning approach, Figure 14 shows the computed and predicted friction velocity at both the toe of the slope, at a shoaling position and at the shore, for 13 of the 14 cases simulated in Part 1, sampled at 2 second intervals. The only case not included is case S030L, which ran up as a undular bore. In this case sometimes the near-bed flow reversed without the outer flow reversing which then caused $a(t) \rightarrow 0$. When the near-bed flow then re-reversed the flow some distance away from the bed had maintained its shape, thus creating a much larger boundary layer and in turn much lower friction velocities than those predicted by (10). It should be noted that, using a standard Manning approach for this case, would also result in poor predictions, as the depth-averaged velocities never changed sign, and thus this approach would at these instants predict the friction velocity with a wrong sign. This case was therefore omitted from Figure 14 as it would make comparison of the models for the remaining cases more difficult. The difficulty predicting this particular case is duly noted, however. From Figure 14 it can clearly be seen that the proposed model improves the prediction of the friction velocity significantly at the toe of the slope (Figure 14a,b) and at the shoaling position (Figure 14c,d), but remains very similar to the prediction using the Manning approach at the shore (Figure 14e,f). The greatest improvement is seen at the higher friction velocities, which correspond to the arrival of the steep wave front where the tsunami-induced boundary layer has not had significant time to grow. At the shore, where wave breaking occurs in many of the cases, the scatter is naturally larger for both methods.

The general way in which the present formulas (8)-(11) are derived and implemented, suggests that they may well also be applicable for shorter waves i.e. that they are not limited to predicting the boundary layer thickness and bed shear stresses from the free-stream velocity signal alone in the tsunami-induced flows considered above. That the developed approach is more generally valid is verified in more detail in Appendix A.

\section{Conclusions}

In this work results from CFD simulations of full scale tsunamis running up different constant sloped regions are presented, with special focus on tsunami-induced boundary layers, bed shear stresses and implications for 
sediment transport. The results presented here are connected to Part 1 (Larsen and Fuhrman, 2018a), where the run-up process from the same full scale simulations were discussed.

Spatial distributions of Shields and Rouse parameters have revealed that, for the cases considered, significant sediment transport could be expected to occur (Shields parameters of up to $\mathrm{O}(10)-\mathrm{O}(100)$ ), and that this sediment transport would in general be dominated by suspended sediment transport, provided that the sediment corresponds to medium sand. Large Rouse parameters beneath the inundating tsunami front have indicated that the sediment in suspension would probably span the entirety of the boundary layer. Furthermore, behind the tsunami front the lower Rouse parameters indicate that suspended sediment transport would still be dominant, but that it would likely be confined to the lower part of the boundary layer. During the draw-down both Shields and Rouse parameters likewise indicate that substantial suspended sediment transport could be expected. This, thus, questions the validity of one of the primary assumptions in many inverse paleo-tsunami research models, namely that sediment will not get re-suspended during draw-down.

Subsequently, the detailed physics of the tsunami-induced boundary layers have been discussed. The observed boundary layer thicknesses have ranged from spanning a small proportion of the water depth to spanning the entire depth. Especially in the non-breaking case considered, the boundary layer rarely stretched the entire depth, at least from the original shoreline and shoreward. In the cases running up as breaking bores, the boundary layers stretched the entire water depth during run up, but during draw-down a new boundary layer formed which was not depth limited.

It has been shown that the temporal variation of the boundary layer thickness can be reasonably predicted using standard empirical engineering formulas, but replacing the orbital amplitude with the cumulative distance travelled by a free-stream particle following each flow reversal. The computed velocity profiles beneath the tsunami have been shown to yield a reasonable match with a logarithmic profile up to the predicted boundary layer thickness.

Finally, it has been shown that the time-varying friction velocity could be similarly well predicted by a simple engineering model based on a timevarying friction factor, while also taking into account the time-varying boundary layer thickness described above. This approach was shown to give better estimates for the friction velocity beneath the steep tsunami wave front than a standard Manning approach, which does not account for the time varying boundary layer thickness. 
The new approach is also shown to give accurate predictions of the bed shear stresses for much shorter waves across a wide range of $a / k_{s}$ as well as both sinusoidal, asymmetric, skewed and irregular short waves in Appendix A. Both the engineering model for the time-varying boundary layer thickness and the friction velocity can easily be implemented in any NLSW or Boussinesq wave model, potentially improving their ability to predict sediment transport beneath tsunamis (or much shorter waves). This can prove valuable in assessing the impact of tsunamis on coastal regions.

\section{Acknowledgements}

The authors acknowledge support from the European Union project ASTARTE-Assessment, Strategy And Risk Reduction for Tsunamis in Europe, Grant no. 603839 (FP7-ENV-2013.6.4-3). The authors likewise acknowledge financial support from the Independent Research Fund Denmark project SWASH: Simulating WAve Surf-zone Hydrodynamics and sea bed morphology, Grant no. 8022-00137B The authors finally acknowledge Dominic A. van der A for providing the data used for comparison in Figure A.16 as well as Jian Yuan for providing the data used for comparison in Figure A.17.

Abreu, T., Michallet, H., Silva, P. A., Sancho, F., van der A, D. A., Ruessink, B. G., 2013. Bed shear stress under skewed and asymmetric oscillatory flows. Coast. Eng. 73, 1-10.

Apotsos, A., Buckley, M., Gelfenbaum, G., Jaffe, B., Vatvani, D., 2011a. Nearshore tsunami inundation model validation: Toward sediment transport applications. Pure Appl. Geophys. 168 (11), 2097-2119.

Apotsos, A., Gelfenbaum, G., Jaffe, B., 2011b. Process-based modeling of tsunami inundation and sediment transport. J. Geophys. Res. 116 (1), $1-20$.

Apotsos, A., Gelfenbaum, G., Jaffe, B., Watt, S., Peck, B., Buckley, M., Stevens, A., 2011c. Tsunami inundation and sediment transport in a sediment-limited embayment on American Samoa. Earth-Sci Rev. 107 (12), $1-11$.

Baykal, C., Sumer, B. M., Fuhrman, D. R., Jacobsen, N. G., Fredsøe, J., 2015. Numerical investigation of flow and scour around a vertical circular cylinder. Phil. Trans. Roy. Soc. A 373, article no. 20140104. 
Bayraktar, D., Ahmad, J., Larsen, B. E., Carstensen, S., Fuhrman, D. R., 2016. Experimental and numerical study of wave-induced backfilling beneath submarine pipelines. Coast. Eng. 118, 63-75.

Borrero, J. C., Synolakis, C. E., Fritz, H., 2006. Northern Sumatra field survey after the December 2004 Great Sumatra earthquake and Indian Ocean tsunami. Earthquake Spectra 22 (3), S93-S104.

Cheng, W., Weiss, R., 2013. On sediment extent and runup of tsunami waves. Earth and Planetary Science Letters 362, 305-309.

Fredsøe, J., 1984. Turbulent wave boundary layer in wave-current motion. J. Hydraul. Eng. ASCE 110, 1103-1120.

Fredsøe, J., Deigaard, R., 1992. Mechanics of Coastal Sediment Transport. World Scientific, Singapore.

Fuhrman, D. R., Baykal, C., Sumer, B. M., Jacobsen, N. G., Fredsoe, J., 2014. Numerical simulation of wave-induced scour and backfilling processes beneath submarine pipelines. Coast. Eng. 94, 10-22.

Fuhrman, D. R., Schløer, S., Sterner, J., 2013. RANS-based simulation of turbulent wave boundary layer and sheet-flow sediment transport processes. Coast. Eng. 73, 151-166.

Gonzalez-Rodriguez, D., Madsen, O. S., 2007. Seabed shear stress and bedload transport due to asymmetric and skewed waves. Coast. Eng. 54, 914-929.

Gonzalez-Rodriguez, D., Madsen, O. S., 2011. Boundary-layer hydrodynamics and bedload sediment transport in oscillating water tunnels. J. Fluid Mech. 667, 48-84.

Jacobsen, N. G., Fuhrman, D. R., Fredsøe, J., 2012. A wave generation toolbox for the open-source CFD library: OpenFOAM (R). Int. J. Numer. Meth. Fluids 70, 1073-1088.

Jaffe, B. E., Gelfenbuam, G., 2007. A simple model for calculating tsunami flow speed from tsunami deposits. Sedimentary Geol. 200 (3-4), 347-361.

Jensen, B. L., Sumer, B. M., Fredsøe, J., 1989. Turbulent oscillatory boundary layers at high Reynolds numbers. J. Fluid Mech. 206, 265-297. 
Johnson, J. P. L., Delbecq, K., Kim, W., Mohrig, D., 2016. Experimental tsunami deposits: Linking hydrodynamics to sediment entrainment, advection lengths and downstream fining. Geomorphology 253, 478-490.

Kato, F., Noguchi, K., Suwa, Y., Sakagami, T., Sato, Y., 2012. Field survey on tsunami-induced topographical change. Journal of Japan Society of Civil Engineers, Ser. B3 68 (2), 174-179.

Kuriyama, Y., Takahashi, K., Yanagishima, S., Tomita, T., 2014. Beach profile change at Hasaki, Japan caused by 5 -m-high tsunami due to the 2011 off the Pacific coast of Tohoku earthquake. Mar. Geol. 355, 234-243.

Lacy, J. R., Rubin, D. M., Buscombe, D., 2012. Currents, drag, and sediment transport induced by a tsunami. J. Geophys. Res.- Oceans 117 (9), article no. C0928.

Larsen, B. E., 2018. Tsunami-seabed interactions. Ph.D. thesis, Technical University of Denmark, Kgs. Lyngby, Denmark.

Larsen, B. E., Arbøll, L. K., Frigaard, S., Carstensen, S., Fuhrman, D. R., 2018. Experimental study of tsunami-induced scour around a monopile foundation. Coast. Eng. 138, 9-21.

Larsen, B. E., Fuhrman, D. R., 2018a. Full-scale CFD simulation of tsumanis. Part 1: Model validation and run-up. Submitted. Referred to as Part 1 .

Larsen, B. E., Fuhrman, D. R., 2018b. On the over-production of turbulence beneath surface waves in Reynolds-averaged Navier-Stokes models. J. Fluid Mech. 853, 419-460.

Larsen, B. E., Fuhrman, D. R., Baykal, C., Sumer, B. M., 2017. Tsunamiinduced scour around monopile foundations. Coast. Eng. 129, 36-49.

Larsen, B. E., Fuhrman, D. R., Sumer, B. M., 2016. Simulation of waveplus-current scour beneath submarine pipelines. J. Waterw. Port C-ASCE 142 (5), article no. 04016003.

Li, L., Qiu, Q., Huang, Z., 2012. Numerical modeling of the morphological change in Lhok Nga, West Banda Aceh, during the 2004 Indian Ocean tsunami: understanding tsunami deposits using a forward modeling method. Nat. Haz. 64 (2), 1549-1574. 
Lu, S., Liu, H., Deng, X., 2018. An experimental study of the run-up process of breaking bores generated by dam-break under dry- and wet-bed conditions. J. Earthquake and Tsunami 12 (2), 1840005.

Madsen, P. A., Fuhrman, D. R., 2008. Run-up of tsunamis and long waves in terms of surf-similarity. Coast. Eng. 55, 209-223.

Madsen, P. A., Schäffer, H. A., 2010. Analytical solutions for tsunami runup on a plane beach. J. Fluid Mech. 645, 27-57.

Moore, A. L., McAdoo, B. G., Ruffman, A., 2007. Landward fining from multiple sources in a sand sheet deposited by the 1929 Grand Banks tsunami, Newfoundland. Sedimentary Geol. 200 (3-4), 336-346.

Nielsen, P., 1992. Coastal Bottom Boundary Layers and Sediment Transport. World Scientific, Singapore.

Nielsen, P., 2002. Shear stress and sediment transport calculations for swash zone modelling. Coast. Eng. 45 (1), 53-60.

Nielsen, P., 2006. Sheet flow sediment transport under waves with acceleration skewness and boundary layer streaming. Coast. Eng. 53 (9), 749-758.

Nielsen, P., Callaghan, D. P., 2003. Shear stress and sediment transport calculations for sheet flow under waves. Coast. Eng. 47, 347-354.

O’Donoghue, T., Pokrajac, D., Hondebrink, L. J., 2010. Laboratory and numerical study of dambreak-generated swash on impermeable slopes. Coast. Eng. 57 (5), 513-530.

Ontowirjo, B., Paris, R., Mano, A., 2013. Modeling of coastal erosion and sediment deposition during the 2004 Indian Ocean tsunami in Lhok Nga, Sumatra, Indonesia. Nat. Haz. 65 (3), 1967-1979.

Paris, R., Wassmer, P., Sartohadi, J., Lavigne, F., Barthomeuf, B., Desgages, E., Grancher, D., Baumert, P., Vautier, F., Brunstein, D., Gomez, C., 2009. Tsunamis as geomorphic crises: Lessons from the December 26, 2004 tsunami in Lhok Nga, West Banda Aceh (Sumatra, Indonesia). Geomorphology 104 (1-2), 59-72.

Soulsby, R. L., Smith, D. E., Ruffman, A., 2007. Reconstructing tsunami run-up from sedimentary characteristics - a simple mathematical model. Coastal Sediments '07 - Proceedings of 6th International Symposium on Coastal Engineering and Science of Coastal Sediment Processes. 
Sugawara, D., Goto, K., Jaffe, B. E., 2014a. Numerical models of tsunami sediment transport - current understanding and future directions. Mar. Geol. 352, 295-320.

Sugawara, D., Takahashi, T., Imamura, F., 2014b. Sediment transport due to the 2011 Tohoku-Oki tsunami at Sendai: Results from numerical modeling. Mar. Geol. 358, 18-37.

Sumer, B. M., Fredsøe, J., 2002. The Mechanics of Scour in the Marine Environment. World Scientific, Singapore.

Suppasri, A., Muhari, A., Ranasinghe, P., Mas, E., Shuto, N., Imamura, F., Koshimura, S., 2012. Damage and reconstruction after the 2004 Indian Ocean tsunami and the 2011 Great East Japan tsunami. J.l Nat. Disaster Sc. 34 (1), 19-39.

Tanaka, H., Adityawan, M. B., Mitobe, Y., Widiyanto, W., 2016. A new computation method of bottom shear stress under tsunami waves. J. Coast. Res. 1 (75), 1247-1251.

Terrile, E., Reniers, A. J. H. M., Stive, M. J. F., 2009. Acceleration and skewness effects on the instantaneous bed-shear stresses in shoaling waves. J. Waterw. Port C-ASCE 135 (5), 228-234.

Udo, K., Takeda, Y., Tanaka, H., 2016. Coastal morphology change before and after 2011 off the Pacific coast of Tohoku earthquake tsunami at Rikuzen-Takata coast. Coast. Eng. J. 58 (4), 1640016.

van der A, D. A., O’Donoghue, T., Davies, A. G., Ribberink, J. S., 2011. Experimental study of the turbulent boundary layer in acceleration-skewed oscillatory flow. J. Fluid Mech. 684, 251-283.

Wilcox, D. C., 2006. Turbulence Modeling for CFD, 3rd Edition. DCW Industries, Inc., La Canada, California.

Williams, I. A., Fuhrman, D. R., 2016. Numerical simulation of tsunamiscale wave boundary layers. Coast. Eng. 110, 17-31.

Yamashita, K., Sugawara, D., Takahashi, T., Imamura, F., Saito, Y., Imato, Y., Kai, T., Uehara, H., Kato, T., Nakata, K., Saka, R., Nishikawa, A., 2016. Numerical simulations of large-scale sediment transport caused by the 2011 Tohoku earthquake tsunami in Hirota Bay, Southern Sanriku Coast. Coast. Eng. J. 58 (4), article no.1640015. 
865 Yoshii, T., Tanaka, S., Matsuyama, M., 2017. Tsunami deposits in a super-

$866 \quad$ large wave flume. Mar. Geol. 391, 98-107.

867 Yoshii, T., Tanaka, S., Matsuyama, M., 2018. Tsunami inundation, sediment 868 transport, and deposition process of tsunami deposits on coastal lowland 869 inferred from the tsunami sand transport laboratory experiment (tstle). 870 Mar. Geol. 400, 107-118.

871 Yuan, J., Dash, S. M., 2017. Experimental investigation of turbulent wave 872 boundary layers under irregular coastal waves. Coast. Eng. 128, 22-36.

873 Yuan, J., Madsen, O. S., 2015. Experimental and theoretical study of wave874 current turbulent boundary layers. J. Fluid Mech. 765, 480-523. 

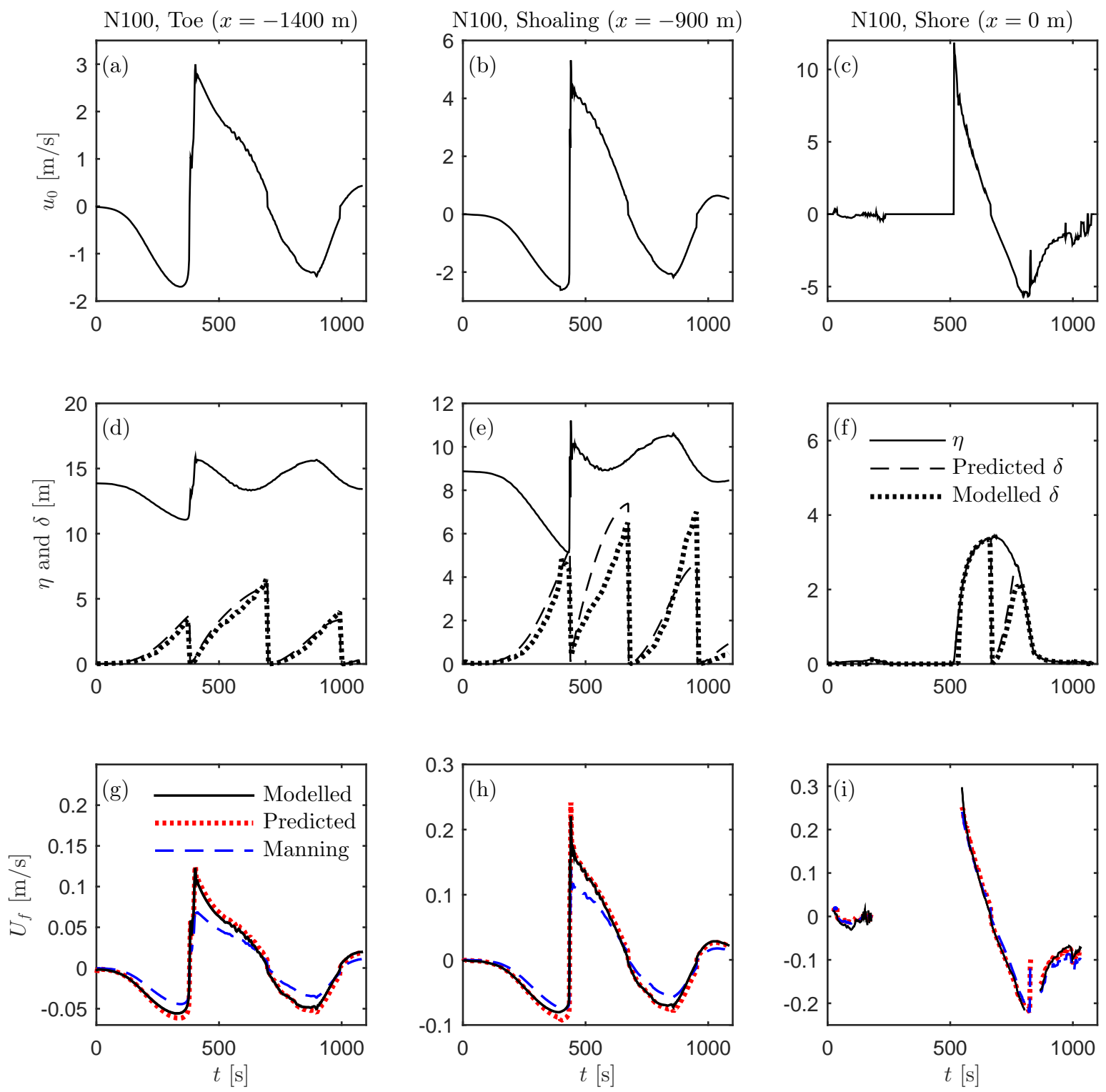

Figure 12: Time series of free-stream velocities (a)-(c), surface elevation and boundary layer thickness (d)-(f) and friction velocities (g)-(i) for case N100 at the toe of the slope $(x=-1400 \mathrm{~m})$, at one shoaling position $(x=-900 \mathrm{~m})$ and at the shore $(x=0 \mathrm{~m})$. Root mean square erros (RMSE) with modelled $U_{f}$ : $\mathrm{RMSE}_{\text {Predicted,toe }}=0.004 \mathrm{~m} / \mathrm{s}, \mathrm{RMSE}_{\text {Manning,toe }}=0.013 \mathrm{~m} / \mathrm{s}, \mathrm{RMSE}_{\text {Predicted,shoaling }}=$

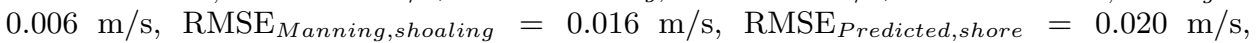
$\mathrm{RMSE}_{\text {Manning,shore }}=0.023 \mathrm{~m} / \mathrm{s}$. 

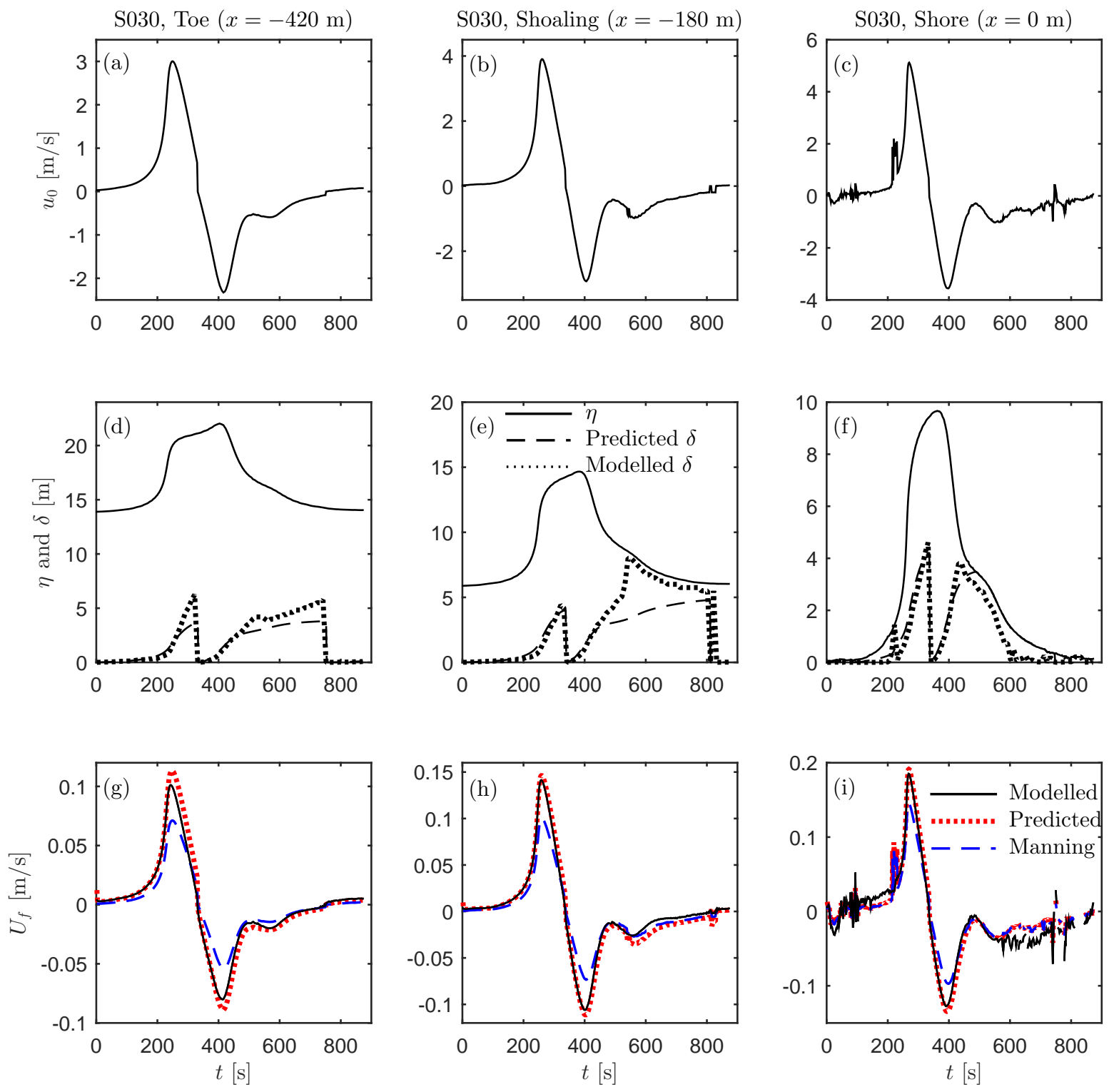

Figure 13: Time series of free-stream velocities (a)-(c), surface elevation and boundary layer thickness (d)-(f) and friction velocities (g)-(i) for case S030 at the toe of the slope $(x=-420 \mathrm{~m})$, at one shoaling position $(x=-180 \mathrm{~m})$ and at the shore $(x=0$ $\mathrm{m})$. RMSE with modelled $U_{f}: \mathrm{RMSE}_{\text {Predicted,toe }}=0.006 \mathrm{~m} / \mathrm{s}, \mathrm{RMSE}_{\text {Manning,toe }}=$ $0.011 \mathrm{~m} / \mathrm{s}, \mathrm{RMSE}_{\text {Predicted,shoaling }}=0.006 \mathrm{~m} / \mathrm{s}, \mathrm{RMSE}_{\text {Manning,shoaling }}=0.013 \mathrm{~m} / \mathrm{s}$, $\mathrm{RMSE}_{\text {Predicted,shore }}=0.013 \mathrm{~m} / \mathrm{s}, \mathrm{RMSE}_{\text {Manning, shore }}=0.016 \mathrm{~m} / \mathrm{s}$. 

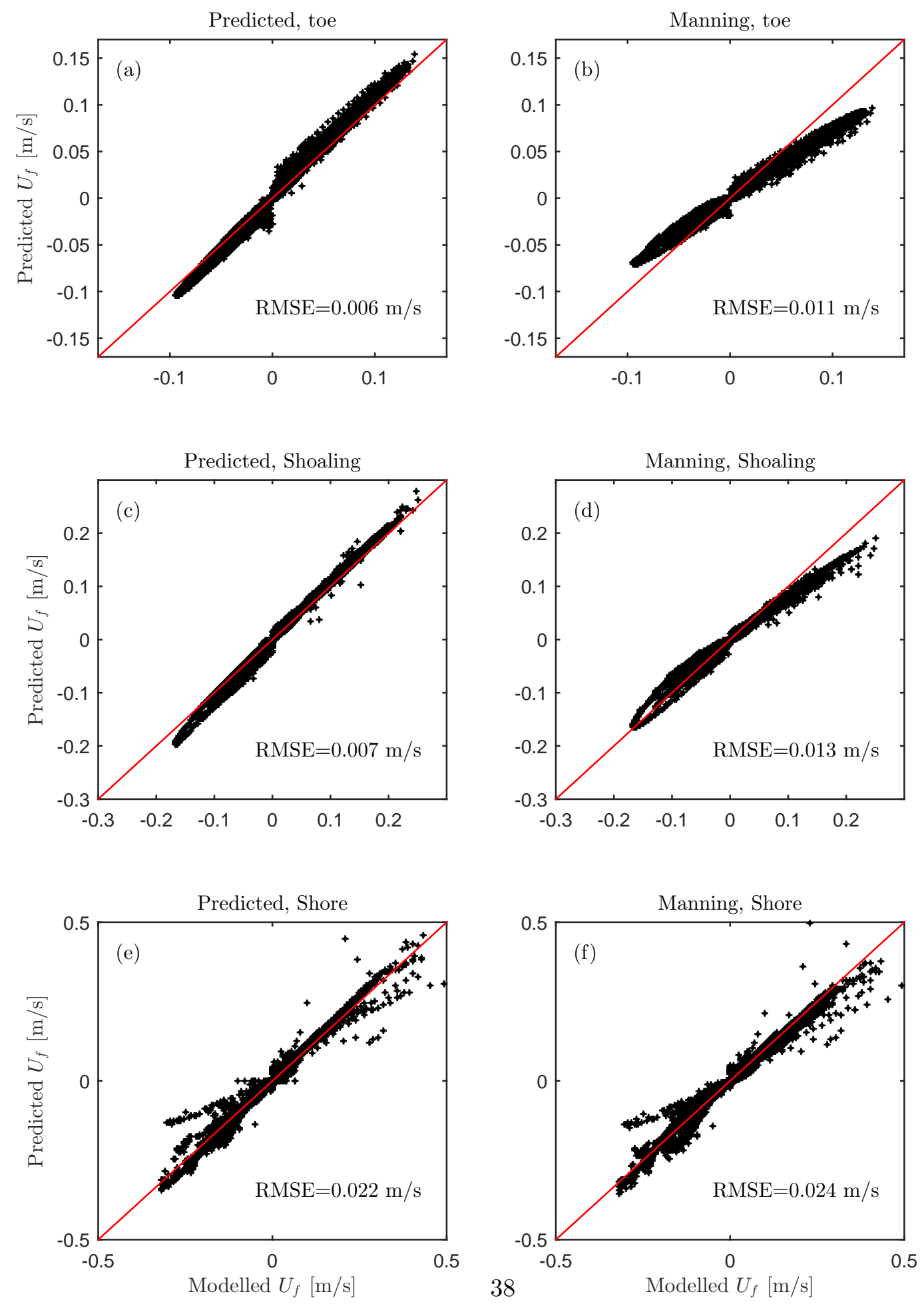

Figure 14: Comparison of modelled and predicted friction velocities using both the new engineering model (10) and the Manning approach (14). (-) marks the line of perfect agreement. 


\section{Appendix A. General applicability of the engineering model}

We have argued in the main text that the general way in which the engineering approach for predicting bed shear stresses from the free-stream velocity alone has been derived and formulated might make it suitable also for shorter waves. The performance of the engineering model will be demonstrated in this section, but first a small introduction to the literature involving the prediction of time varying bed shear stress will be given.

One of the key factors in predicting sediment transport is accurately predicting the bed shear stress. This is by no means an easy task, and has been the focus of much research. The task is particularly difficult in the surf and swash zone where the free stream velocity signal can become skewed or asymmetric. In a skewed velocity signal the maximum velocity is higher than the minimum. This results in higher onshore bed shear stresses. In an asymmetric signal the acceleration is skewed meaning that maximum acceleration is higher than the minimum. This means that the boundary layer has less time to grow during the acceleration phase, and as a result the velocity gradients (and thus the bed shear stresses) are higher during the positive half cycle than the negative. These two phenomena cannot be captured by the standard constant friction factor approach

One of the earliest attempts to predict the time varying shear stress was made by Fredsøe (1984) who used the momentum integral approach together with an assumed logarithmic velocity profile. This approach can handle the problems mentioned above, but involves solving a differential equation, which contains singularities during flow reversal, and obtaining a robust solution for this is not trivial. Another approach to predict the time varying shear stress beneath asymmetric waves was made by Nielsen (1992). He proposed a formula which included both the free stream velocity and the acceleration of the free stream velocity. This was done to take into account the effect of favourable pressure gradients in asymmetric waves. This approach was, however, built on a laminar boundary layer, and in Nielsen (2002) the approach was extended to turbulent flows. In this paper Nielsen argued for a phase shift of around $45^{\circ}$ between the bed shear stress and the free stream velocity. The reason for this phase shift was that it gave better correspondence with experimental vertical sediment fluxes. Nielsen and Callaghan (2003) further extended this approach to also take into account streaming effects. The model was further calibrated by Nielsen (2006), but overall the approach was similar, i.e to calculate the bed shear stress from free stream velocity and the free stream acceleration accounting for a phase shift, but keeping a constant friction factor. The approach initiated by the 
various works by Nielsen and colleagues was further extended by Terrile et al. (2009) who included a waveform parameter and by generalizing the velocity signals as a sum of harmonics. Finally Abreu et al. (2013) extended this by including an analytical expression capable of generating both skewed and asymmetric waves.

Another approach was taken by Gonzalez-Rodriguez and Madsen (2007). In their approach the friction factor was time varying. Their friction factor was first estimated for both the crest and the trough of the wave and then interpolated linearly for the entire period. Additionally, a function for the phase shift between the free-stream velocity signal and the bed shear stress was utilized. This model, in general, compared well against a RANS model.

Gonzalez-Rodriguez and Madsen (2011) developed an analytical model of the turbulent boundary-layer by using a time-varying eddy viscosity and gave analytical expressions to compute the bed shear stresses for asymmetric and skewed waves, both in the absence or presence of an imposed current. For this approach the free stream velocity signal was decomposed into its first two harmonics and the analysis provided the first three harmonics of the bed shear stress. Decomposing the free-stream velocity signal into Fourier components was also done in the semi-analytical study of Yuan and Madsen (2015) who extended the work by Gonzalez-Rodriguez and Madsen (2011). They no longer assumed first-and second-harmonic contributions to the function $f(t)$ multiplied by the mean eddy viscosity profile to be small and showed that this gave better predictions for forward leaning waves.

The above studies have shown promising results, but also have some limitations. All mentioned studies, except Fredsøe (1984), Gonzalez-Rodriguez and Madsen (2011) and Yuan and Madsen (2015), require a priori knowledge of the period and phase shift. This is not the case in the studies by Gonzalez-Rodriguez and Madsen (2011) and Yuan and Madsen (2015). These require a Fourier decomposition of the entire signal, however. This means that none of the studies above can be straight-forwardly used on an arbitrary instantaneous velocity signal, which could show up e.g. in a potential (wave resolving) flow model. Furthermore, it is also questionable how some of these models would handle the situation where the boundary layer at some point extends all the way to the free surface as could occur in a tsunami. Finally, all of the models (except for the momentum integral approach) require some kind of periodicity, and it is therefore questionable how they would behave in a situation e.g. where the flow is accelerated from zero to a fixed maximum value.

The engineering approach for predicting the friction velocity, presented in this paper, again based on (9)-(13), is designed to handle all of the chal- 


\begin{tabular}{ccccccc}
\hline Study & $a / k_{s}$ & $R e$ & Shape & Signal & $T[\mathrm{~s}]$ & $U_{m}[\mathrm{~m} / \mathrm{s}]$ \\
\hline Jensen et al. (1989) & 3700 & $6 \times 10^{6}$ & sinusoidal & regular & 9.82 & 2 \\
van der A et al. (2011) & 90 & $1 \times 10^{6}$ & acceleration-skewed & regular & 7 & 1.1 \\
Yuan and Dash (2017) & $300^{*}$ & $1 \times 10^{6 *}$ & velocity + acceleration-skewed & irregular & 6.4 & $1.1^{*}$ \\
\hline
\end{tabular}

Table A.2: Key parameters for the studies used for comparison with the engineering model.

* since these studies were irregular $U_{r m s}=\sqrt{2} s t d\left(u_{0}\right)$ has been used instead of $U_{m}$.

lenges mentioned above. In what follows we will now compare the present model to the well-known experiments of Jensen et al. (1989) which were based on a sinusoidal oscillatory flow, the experiments of van der A et al. (2011) involving acceleration-skewed flows and finally the experiments of Yuan and Dash (2017) which involved random amplitude modulated (with constant period), velocity and- acceleration-skewed flows. These three have been chosen to demonstrate the performance of the engineering approach for free stream signals typical of sinusoidal, velocity-skewed, accelerationskewed and random modulated waves waves, as well as to demonstrate the performance across a wide range of $a / k_{s}$. These will hence complement the applications on the long tsunami waves in the main text. A summary of the cases to be considered is given in Table A.2.

First the model will be compared to the well known test 13 of Jensen et al. (1989). The experiments were conducted in an oscillatory tunnel facility. The free stream velocity signal was sinusoidal with a period $T=9.72 \mathrm{~s}$, maximum free-stream velocity $U_{m}=2 \mathrm{~m} / \mathrm{s}$ and a roughness $k_{s}=0.84$ $\mathrm{mm}$, see Table A.2. Figure A.15 shows the experimental friction velocities as well as that predicted with (9)-(13) based only on the measured freestream velocity $u_{0}$ as input. Included is also the predicted friction velocity using a constant friction factor expression from Fuhrman et al. (2013) in (10) i.e. substituting $a(t)$ with $a$ in (11). It can be seen that the predicted friction velocity matches the experimental well. It can also be seen that the predictions are reasonably in phase with the measurements, whereas the constant friction factor approach is in phase with the free-stream velocity signal i.e. the phase shift between the free-stream velocity signal and the bed shear stress seem to be well captured by only taking into account the effect of the time varying boundary layer thickness and not considering acceleration effects. Near flow reversal there will also be a phase shift due to the adverse pressure gradient turning the near flow before the free-stream. This phase shift will be not be captured with the present approach, but is not considered particularly important, since this is only significant near flow reversal, i.e. when the velocities are small. 


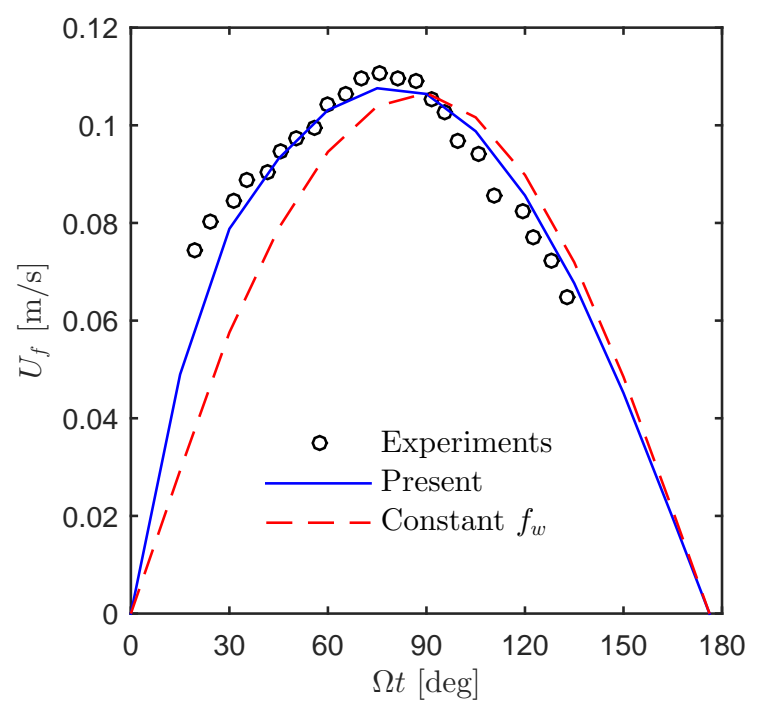

Figure A.15: Comparison of experimentally measured friction velocities (test 13 of Jensen et al. (1989)) with those predicted using (10) and using a constant $f_{w}$.

Having demonstrated the performance of the engineering model for sinusoidal flows it will now be compared to experimental results involving acceleration-skewed flows from van der A et al. (2011). These experiments were conducted in an oscillating flow tunnel. The waves in all three cases had a period $T=7 \mathrm{~s}$, maximum free-stream velocity $U_{m} \approx 1.1 \mathrm{~m} / \mathrm{s}$ and $k_{s}=13.79 \mathrm{~mm}$, with varying degrees of acceleration skewness, quantified by:

$$
\beta=\frac{\dot{u}_{0 \max }}{\dot{u}_{0 \max }-\dot{u}_{0 \min }}
$$

where $\dot{u}_{0}$ is the free-stream acceleration. Specifically the model will be compared to their cases S5071012g, S6071012g and S7571012g having $\beta=$ $0.5,0.6$ and 0.75 respectively (note that $\beta=0.5$ correspond to a sinusoidally varying flow).

Figure A.16 shows the experimental and predicted time series of the friction velocity using both (10) and a constant friction factor approach similarly to before. Here it can be seen that the present model captures well the measured friction velocity and is again able to reasonably capture the phase shift between the friction velocity and the free-stream velocity. In contrast, the predictions using a fixed $f_{w}$ are in phase with the free-stream velocity signal, and do not capture the increased bed shear stress associated 

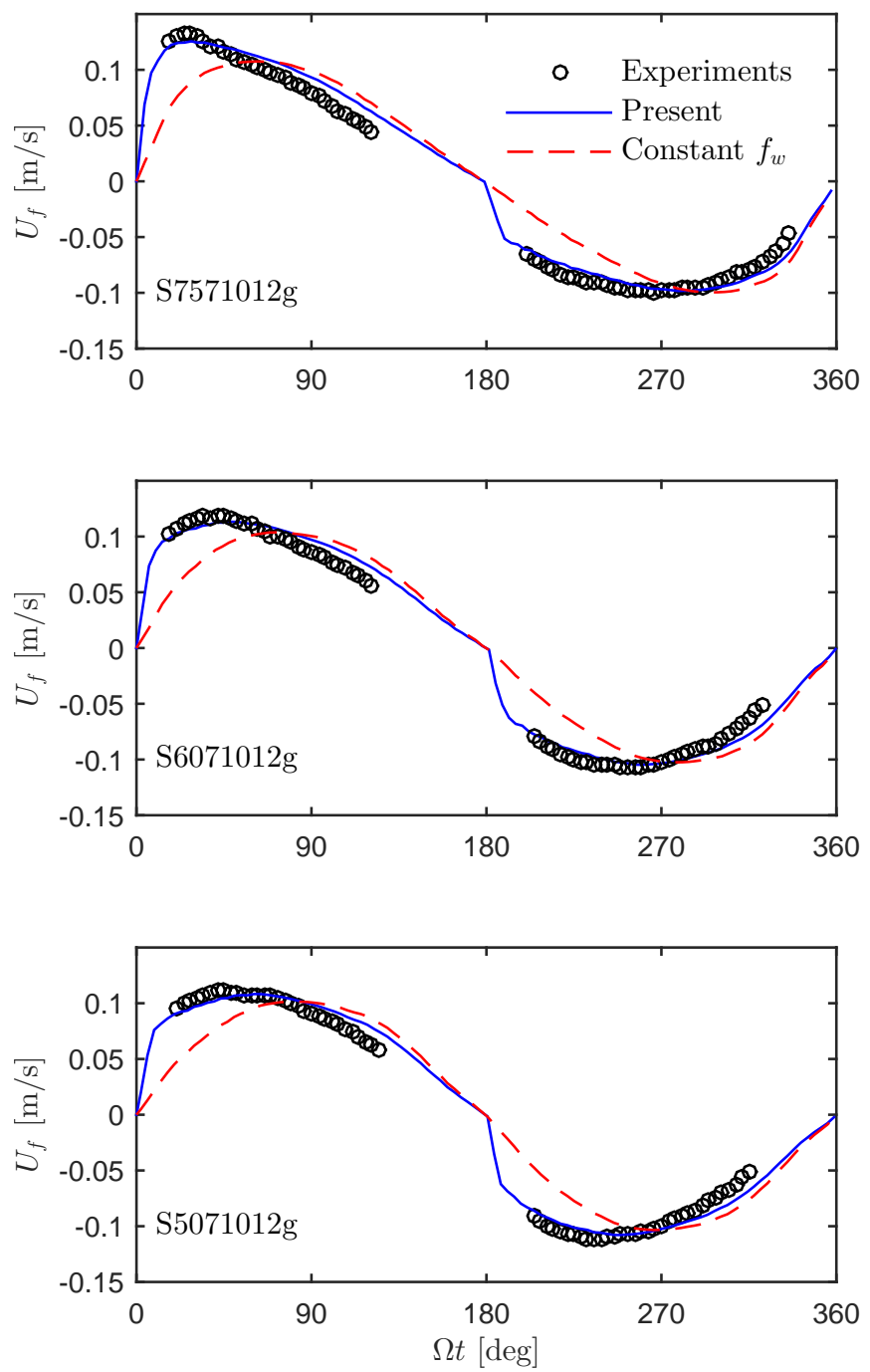

Figure A.16: Comparison of experimentally measured friction velocities beneath acceleration skewed free-stream flows (van der A et al., 2011) with those predicted using (10) and using a constant $f_{w}$.

with the smaller boundary layer thickness.

Finally, the present engineering model will be compared to experiments 1006 from Yuan and Dash (2017). These experiments were performed in an 1007 oscillating water tunnel. The velocity signals consisted of random ampli- 
tude modulated flows with a constant period of $T=6.4 \mathrm{~s}$ and $u_{r m s}=$ $\sqrt{2} \operatorname{std}\left(u_{0}\right)=1.1 \mathrm{~m} / \mathrm{s}$. These flows were in one of the experiments velocityskewed, and in another acceleration-skewed. The bed had a roughness $k_{s}=3.7 \mathrm{~mm}$. Figure A.17 shows the comparison between the measured and predicted friction velocity for both irregular velocity-skewed oscillatory flows (Figure A.17a) and irregular acceleration-skewed oscillatory flows (Figure A.17b). The predicted friction velocity has again been found using both (10) and a constant friction factor approach, using the measured $u_{0}$ as input. In general it can be seen that the engineering model, with no adjustment, predicts well the friction velocity for the irregular oscillatory flows. There is a small underestimation of the friction velocity beneath the peak, but this underestimation is of the same order of magnitude as the scatter in the experiments on which (11) is built (see Fuhrman et al., 2013). Similar to the previous cases, it seems that the phase shift is reasonably captured by incorporating the effect of the time varying boundary layer thickness alone. In comparison, the results using a constant friction factor approach seem to capture as well as (10) the magnitude of the friction velocity of the largest waves, but underestimate the magnitude of the smaller waves, and does not capture the phase shift.

The present engineering model for the friction velocity has thus been shown to be able to accurately predict the time variation of the friction velocity for a wide range of situations, again based only on the free-stream velocity signal. These involve the long unsteady tsunami-induced flows covered in the main text, as well as a range of flows that would typically occur beneath sinusoidal, velocity-skewed regular short waves as well as velocityskewed and acceleration-skewed irregular short wave signals. As discussed in the main text, the simple way the approach is formulated enables it to be implemented in potential flow models, possibly improving their predictions of sediment transport. In the present formulations, the wave friction factor expression from Fuhrman et al. (2013) has been used, though the method may easily be adjusted to use any other friction factor formulations from the literature. 

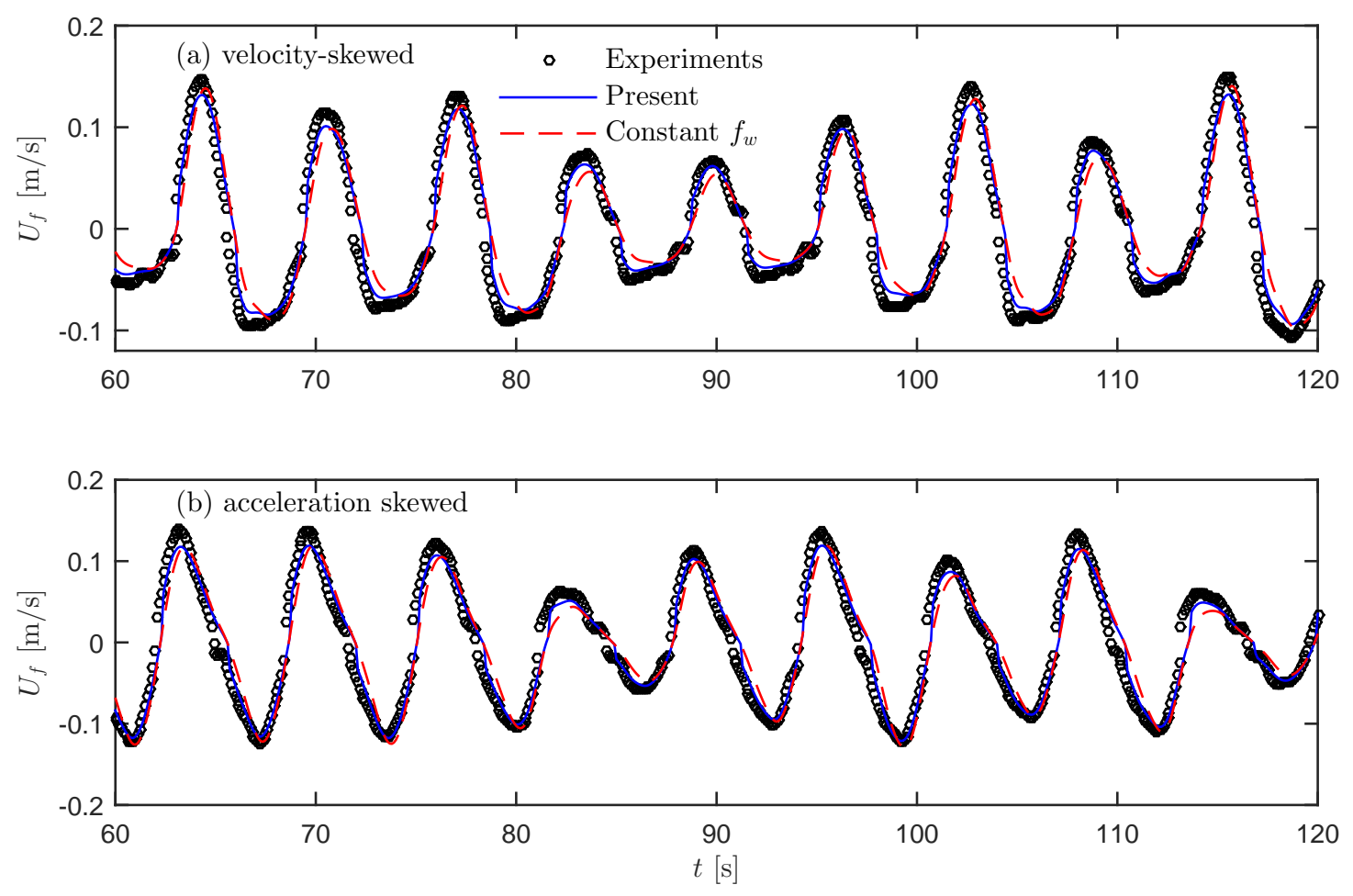

Figure A.17: Comparison of experimentally measured friction velocities beneath (a) velocity-skewed irregular free-stream flows and (b) acceleration-skewed irregular freestream flows (Yuan and Dash, 2017) with those predicted using (10) and using a constant $f_{w}$. 